INTERIM REPORT

\title{
OXYGEN ENRICHMENT \\ FOR OPEN CYCLE \\ MAGNETOHYDRODYNAMIC \\ POWER SYSTEMS
}

\section{Prepared For \\ The United States Department of Energy \\ Division of Magnetohydrodynamics \\ Contract No. ET-78-C-01-2688}

JUNE 1979

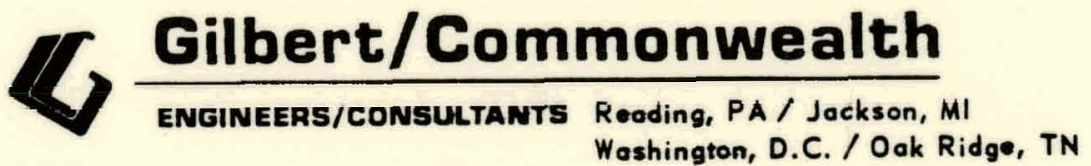




\section{DISCLAIMER}

This report was prepared as an account of work sponsored by an agency of the United States Government. Neither the United States Government nor any agency Thereof, nor any of their employees, makes any warranty, express or implied, or assumes any legal liability or responsibility for the accuracy, completeness, or usefulness of any information, apparatus, product, or process disclosed, or represents that its use would not infringe privately owned rights. Reference herein to any specific commercial product, process, or service by trade name, trademark, manufacturer, or otherwise does not necessarily constitute or imply its endorsement, recommendation, or favoring by the United States Government or any agency thereof. The views and opinions of authors expressed herein do not necessarily state or reflect those of the United States Government or any agency thereof. 


\section{DISCLAIMER}

Portions of this document may be illegible in electronic image products. Images are produced from the best available original document. 


\section{NOTICE}

This report was prepared as an account of work sponsored by the United States Government. Neither the United States nor the United States Department of Energy, nor any of their employees, nor any of their contractors, subcontractors, or their employees, makes any warranty, expressed or implied, or assumes any legal liability or responsibiltty for the accuracy, completeness or usefulness of any information, apparatus, product or process disclosed, or represents that its use would not infringe privately-owned rights. Mention of commercial products, their manufacturers, or their suppliers in this publication does not imply or connote approval or disapproval of the product by Gilbert Associates, Inc.

or the U. S. Department of Energy. 
INTERIM REPORT

\section{OXYGEN ENRICHMENT \\ FOR OPEN CYCLE MAGNETOHYDRODYNAMIC \\ POWER SYSTEMS}

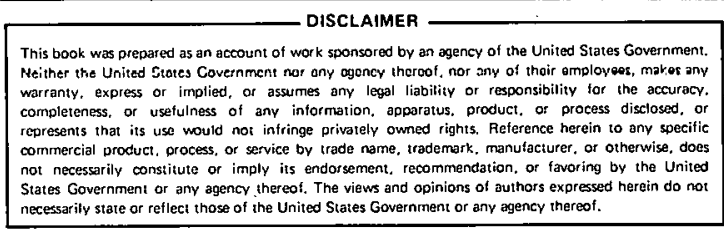

PREPARED FOR

THE UNITED STATES DEPARTMENT OF ENERGY

DIVISION OF MAGNETOHYDRODYNAMICS

CONTRACT NO. ET-78-C-01-2688

\section{GILBERT/COMMONWEAI_TH \\ READING, PA. \\ JUNE 1979}


TABLE OF CONTENTS

Section

Page

Table of Contents $\ldots \ldots \ldots \ldots \ldots \ldots \ldots \ldots \ldots \ldots \ldots \ldots \ldots \ldots \ldots \ldots \ldots$

List of Figures........................ ii

List of Tables............................ ii

Executive Summary....................... iv

1.0 . Purpose and Scope........................... 1

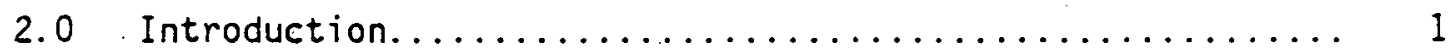

3.0 Previous Studies........................... 3

4.0 Assumptions, Ground Rules and Analytical Basis.......... 3

4.1 Fuel Properties..................... 3

4.2 Combustion Properties.................. 3

4.3 Flame Temperature..................... 6

4.4 Thermal Properties of Plasma.............. 6

5.0 System Effects of Oxygen Enrichment............. 6

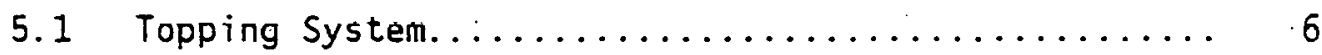

5.2 Bottoming System.................... 11

5.3 System Performance...................... 11

6.0 Economics of Oxygen Enrichment................ 22

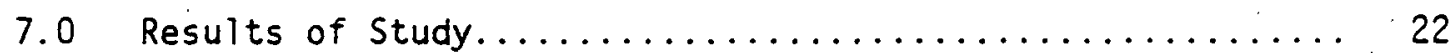

7.1 Conclusions........................... 22

7.2 Recommendations for Further Study............ 23

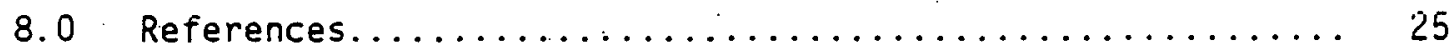

$\begin{array}{lr}\begin{array}{ll}\text { Appendix A - } & \text { Oxygen Enrichment Effects on MHD Channel } \\ & \text { Performance }\end{array} \\ \text { Appendix B - Combustion Gas Properties } & B-1\end{array}$


Figure

5-1

5-2

5-3

5-4

5-5

$5-6$

5-7

5-8

5-9

$5-10$

5-1I
Title

Page

Combustor Flame Temperature vs. Air. Preheat Temperature

Electrical Conductivity vs. Temperature

9

Oxidizer Mass Flow vs. Oxygen Enrichment

10

Oxygen Enriched MHD System with Separately

Fired Preheaters

Oxygen Enriched MHO System with Directly

Fired Preheaters

Plant Efficiency as a Function of Oxygen Enrichment

Channel Power Output as a Function of Combustor Pressure

Diffuser. Exit Temperature as a Function of Combustor Pressure

Plant Efficiency as a Function of Oxygen Enrichment for a $70 \%$ MHD Channel Adiabatic Efficiency

Plant Efficiency as a Function of Oxygen Enrichment for an $85 \%$ MHD Channel. Adiabatic Efficiency

Plant Efficiency as a Function of Oxygen

Enrichment for a 100\% MHD Channe? Adiabatic Efficiency 


\section{LIST OF TABLES}

Table

Title

Page

I

Coal UTtimate Analysis

5

- iij- 


\section{Executive Summary}

Efficient coal fired, open cycle MHD power generation systems require a combustion flame temperature of approximately $4600 \mathrm{~F}$ to provide adequate electrical conductivity in the MHD gas. To achieve this high flame temperature, either highly preheated combustion air or oxygen enrichment of combustion air preheated to a lower temperature is required. Since directly and separately fired high temperature air preheaters are not sufficiently advanced in development to ensure their reliable operation in near term MHD syśtems, oxygen enrichment may be the practical alternative for obtaining required flame temperatures in the near future.

The work presented in this interim report is a preliminary evaluation of economic and performance effects due to oxygen enrichment of combustion air in open cycle MHD power systems. This work is part of a continuing series of studies on performance and economics of MHD systems conducted by Gilbert/Commonwealth for the U.S. Department of Energy, Division of Magnetohydrodynamics (DOE/MHD). This interim report summarizes preliminary results obtained through June, 1979. Continued studies on oxygen enrichment are planned for 1980 and will be summarized in a subsequent report.

To help assess the oxygen enrichment alternative, DOE/MHD requested Gilbert/Commonwealth to:

- Conduct a literature survey of related oxygen enrichment studies and review these studies for pertinent results.

- Perform calculations, based on previous work by Gilbert and others, to provide an independent assessment of the potential of utilizing oxygen enrichment in open cycle MHD power generation systems. 
The following conclusions were developed from the literature survey:

- Oxygen enrichment does not offer a significant thermodynamic or economic advantage over an air preheater system if air preheat temperatures of at least $2500 \mathrm{~F}$ to $2700 \mathrm{~F}$ can be reliably achieved.

- With lower preheat temperatures in the range $1300 \mathrm{~F}$ to $1500 \mathrm{~F}$, oxygen enrichment is necessary to achieve the combustor flame temperatures required for high power plant performance.

- For near term MHD power plants, an attractive alternative to the development of high temperature air heaters is a system using a metallic low temperature air heater with oxygen enrichment.

Several operational characteristics of oxygen enriched systems were identified in this study through additional calculations, as part of an independent assessment of system performance. Mollier diagrams for the MHD gas were prepared over the complete range of oxygen enrichment. The MHO generator was simulated by a Brayton cycle model to facilitate the preliminary analysis. Due to the preliminary nature of these analytical results, the data can be used only for comparison of effects from oxygen enrichiment using the cycle data presented in this report.

Preliminary analytical results in this study indicate the following effects on cycle performance due to oxygen enrichment:

- Oxygen enrichment can be used in conjunction with high temperature air heaters for preliminary testing of components, as an alternative system in the event of a total or partial failure of the high temperature air heater system, or to provide adjustments to the channel power output for load following. 
- The combustion gas electrical conductivity, at a given pressure and temperature, is lower with oxygen enrichment compared to a system with only air preheating.

- For a fixed combustor thermal. input, the total mass flow rate through the channel is lower for an oxygen enriched system compared to an air. system. Reduced total mass flow rate results in smaller components in the MHD topping cycle.

- An oxygen enriched system requires a higher pressure ratio to maintain the same $L / D$ and diffuser exit pressure as a system using only. air.

- An oxygen enriched system may result in a favorable reduction of NOX. 


\subsection{PURPOSE AND SCOPE}

The U.S. Department of Energy, Division of Magnetohydrodynamics, is conducting parallel studies of alternative open cycle MHD power system configurations as part of its national program for commercial development of magnetohydrodynamic: (MHD) electric power generation technology. The purpose of these studies is to evaluate cost and performance potentials of various system configurations for eventual utility and industrial applications. An important element of these studies is an evaluation of the economic and operational effects of utilizing oxygen enrichment of the oxidizer gas stream to enhance system performance. As a part of this effort, DOE requested Gilbert/ Commonwealth to:

1). Undertake a literature search of related oxygen enrichment studies and review these studies for pertinent results.

2) Perform additional calculations, based on previous work by Gilbert and others, and provide an independent assessment of the potential of utilizing oxygen enrichment in open cycle MHD power generation systems.

The purpose of this Interim Report is to summarize the work performed to date by Gilbert/Commonwealth. The report includes the following: (a) results of the literature search, (b) detailed assumptions and ground rules utilized in this study of oxygen enrichment, (c) summarized results of analytical studies, and (d) recommendations for further work.

\subsection{INTRODUCTION}

The successful development and demonstration of open cycle MHD power generation technology is predicated upon the achievement of combustion flame temperatures of approximately $4600^{\circ} \mathrm{F}$. This high temperature 
is necessary to provide gases with adequate levels of electrical conductivity for efficient MHD power generation. With the direct combustion of dried, pulverized coal, this, flame temperature can be attained only with the use of highly preheated combustion air or with the use of oxygen enrichment of combustion air which has been preheated to a lower temperature. High temperature air heaters have not been developed to a level where they can be adapted, with confidence, to an MHD system. It, therefore, appears prudent to consider oxygen enrichment as a possible alternative for obtaining the required flame temperatures in MHD development facilities, demonstration plants and, possibly, in early commercial MHD power plants.

Studies performed by Gilbert/Commonwealth, and summarized in this report, were initiated with a literature search and a comprehensive review of previous studies of oxygen enrichment in MHD systems. Summaries of these studies and their conclusions are contained in Appendix A. Using selected references from the literature as a starting point, sets of ground rules and assumptions (Section 4.0) were established for conducting an updated study with subsonic MHD channels. A NASA-developed computer code (Reference 1 ) for modeling of the combustion products and establishing plasma properties was utilized, with slight modification, to prepare a base of thermal properties. Assuming Montana Rosebud coal and combustion air enriched with oxygen from 0 to $50 \%$ (by mass), a series of Mollier diagrams was prepared for the complete range of oxygen enriched cases (Appendix $B$ ).

Preliminary investigations of MHD channel performance were made for subsonic flow and a fixed ratio of channel length to inlet diameter $(L / D)$. As follow-up to these calculations, studies were performed to model an ideal channel (no heat transfer or frictional losses) and a set of calculations was performed assuming that the MHD topping cycle was replaced by a hypothetical Brayton cycle. Following this preliminary investigation of channel. performance, an analysis was conducted to establish the performance of the entire MHO-steam system. 


\subsection{PREVIOUS STUDIES}

The studies referenced in Appendix $A$ are concerned primarily with MHD cycle efficiency and overall plant performance. The effects of oxygen enrichment on MHD plant component availability and maintainability, as well. as oxygen production techniques and costs, are currently under study and the findings will be published separately.

The results and conclusions developed from the literature survey can be summarized as follows:

- Oxygen enrichment with a preheat temperature of about $2500^{\circ} \mathrm{F}$ or higher does not appear to be thermodynamically or economicaliy advantageous.

- With low temperature preheated air in the range of $1300^{\circ} \mathrm{F}$ to $1500^{\circ} \mathrm{F}$, oxygen enrichment will be necessary to achieve combustor $f l a m e$ temperatures required for MHD system operation.

\subsection{ASSUMPTIONS, GROUND RULES AND ANALYTICAL BASIS OF STUDY}

A modified version of the Chemical. Equilibrium Composition (CEC) computer program, developed by NASA (Reference 1), was used to predict combustor flame temperature plus the thermal and electrical properties of the combustion gases.

\subsection{Fuel Properties}

Montana Rosebud sub-bituminous coal was selected for this study because it is typical of western low sulfur coal and is consistent with other DOE studies. The coal composition assumed was based on a Peabody Coal Company analysis. (Reference 2) of Rosebud coal taken from Peabody's Big Sky Mine. This composition, shown in Table I, was adjusted for expected moisture content in an as-fired condition. 


\title{
4.2 Combustion Properties
}

It has been assumed that $90 \%$ of the slag is removed upstream of the MHD generator in a two stage combustor. The following are the combustor design conditions selected for this study:

- oxidizer

- Stoichiometry

- Slag: Removal

- Seed

- Combustor Heat Loss Efficiency
Air is assumed to contain $22.9 \%$ oxygen by mass and $1.3 \%$ water by mass. Oxygen used for enrichment is dry.

$52 \%$ in the first stage; $95 \%$ in the second stage. (The combustion products leave the combustor fuel rich to minimize NO formation. Secondary combustion occurs downstream of the radiant boiler.)

$90 \%$ in the combustor.

1\% (by mass) potassium at the combustor exhaust.

$2 \%$ of the available coal energy in the first stage combustor.

$0.5 \%$ of the available coal energy in the second stage combustor.

For the purpose of this study, the percentage oxygen enrichment is defined as:

Oxygen Enrichment $=$
(Percent)

\author{
Mass of Oxygen Added \\ Mass of Oxygen Added + Mass of Air
}

$\times 100$ 
TABLE I

COAL ULTIMATE ANALYSIS

Mass Fraction

Component

C

$\mathrm{O}_{2}$

$\mathrm{H}_{2}$

$\mathrm{N}_{2}$

C1

S

$\mathrm{SiO}_{2}$

$\mathrm{Al}_{2} \mathrm{O}$

$\mathrm{CaO}$

$\mathrm{Fe}_{2} \mathrm{O}$

MgO

$\mathrm{TiO}_{2}$

$\mathrm{K}_{2} \mathrm{O}$

$\mathrm{Na}_{2} \mathrm{O}$

$\mathrm{P}_{2} \mathrm{O}_{5}$

$\mathrm{H}_{2} \mathrm{O}$

Undetermined
(Adjusted to As-Fired

Conditions)

0.6422

0.1400

0.0425

0.0069

0.0004

0.0113

0.0631

0.0317

0.0177

0.0149

0.0059

0.0013

0.0007

0.0006

0.0004

0.0200

0.0004

$\overline{1.0000}$

The higher heating value (HHV) is $11,081 \mathrm{BTU} / \mathrm{Ib}$. 


\section{3 Flame Temperature}

A state of chemical equilibrium between the combustion gas species was assumed when calculating the flame temperature.

\section{4 Thermal Properties of Plasma}

Thermal properties of the combustor products were taken from Dow Chemical Company's, "JANAF Thermochemical Data" (Reference 3).

\subsection{SYSTEM EFFECTS OF OXYGEN ENRICHMENT}

\subsection{Topping System}

Oxygen enrichment is not thermodynamically or economically competitive if high air preheat temperatures can be achieved. Most systems analyses performed to date assume that large, reliable high temperature air heaters will be developed to the degree which will permit their use in commercial-size MHD power plants and will be capable of delivering to the combustor preheated air having a temperature between 2500 and $3000^{\circ} \mathrm{F}$. For currently planned test facilities, MHD demonstration plants, and possibly for early commercial MHD power plants, oxygen enrichment provides an alternative which is not necessarily dependent on the development of high temperature air heater technology. With current materials, low temperature metallic recuperative air preheaters can be built which have an upper temperature limit of about $1300^{\circ} \mathrm{F}$ when constructed of stainless steel, and $1500^{\circ} \mathrm{F}$ as an upper limit using super alloys. With this low level of air preheat, oxygen enrichment is necessary for successful MHD plant operation.

Analysis has shown that in order to guarantee a sufficiently high electrical conductivity entering the MHD channel, a combustion gas temperature of at least $4600^{\circ} \mathrm{F}$ must be achieved in the 
combustor. Figure 5-1 shows the expected flame temperature as a function of air preheat temperature and oxygen enrichment for Montana Rosebud coal.

Without oxygen enrichment, an air preheat temperature of $2700^{\circ} \mathrm{F}$ is necessary to produce a combustor flame temperature of $4600^{\circ} \mathrm{F}$. With $10 \%$ oxygen enrichment, an air preheat temperature of $1800^{\circ} \mathrm{F}$ is required for a combustion gas flame temperature of $4600^{\circ} \mathrm{F}$; with about $17 \%$ oxygen enrichment, an air preheat temperature of only $1000^{\circ} \mathrm{F}$ is required.

The effect of oxygen enrichment does not rest entirely with the flame temperature. For a given temperature and pressure, the electrical conductivity of the combustion gas decreases with oxygen addition. This characteristic is shown in Figure 5-2. For a desired electrical conductivity, a higher combustion gas temperature will be needed as the oxygen enrichment is increased. This increased gas temperature will have to be supplied through increased preheater temperature (for a given oxygen enrichment).

Another significant characteristic of an oxygen enriched system is the sensitivity of total flow rate to enrichment. In figure 5-3, the total oxidizer mass flow rate versus percent enrichment is presented. For a given stoichiometry, a fixed quantity of oxygen is required for combustion of a fixed amount of coal. As oxygen enrichment increases, the quantity of oxygen from the air decreases along with a corresponding decrease in nitrogen. The resulting decrease in total mass flow will adversely effect power produced from the topping cycle. There could be, however, a reduction in the nitrogen oxides $\left(\mathrm{NO}_{x}\right)$ production and also a reduction in the size of the topping cycle components. 
FIGURE $5-1$

COMBUSTOR FLAME TEMPERATURE VS. AIR PREHEAT. TEMPERATURE

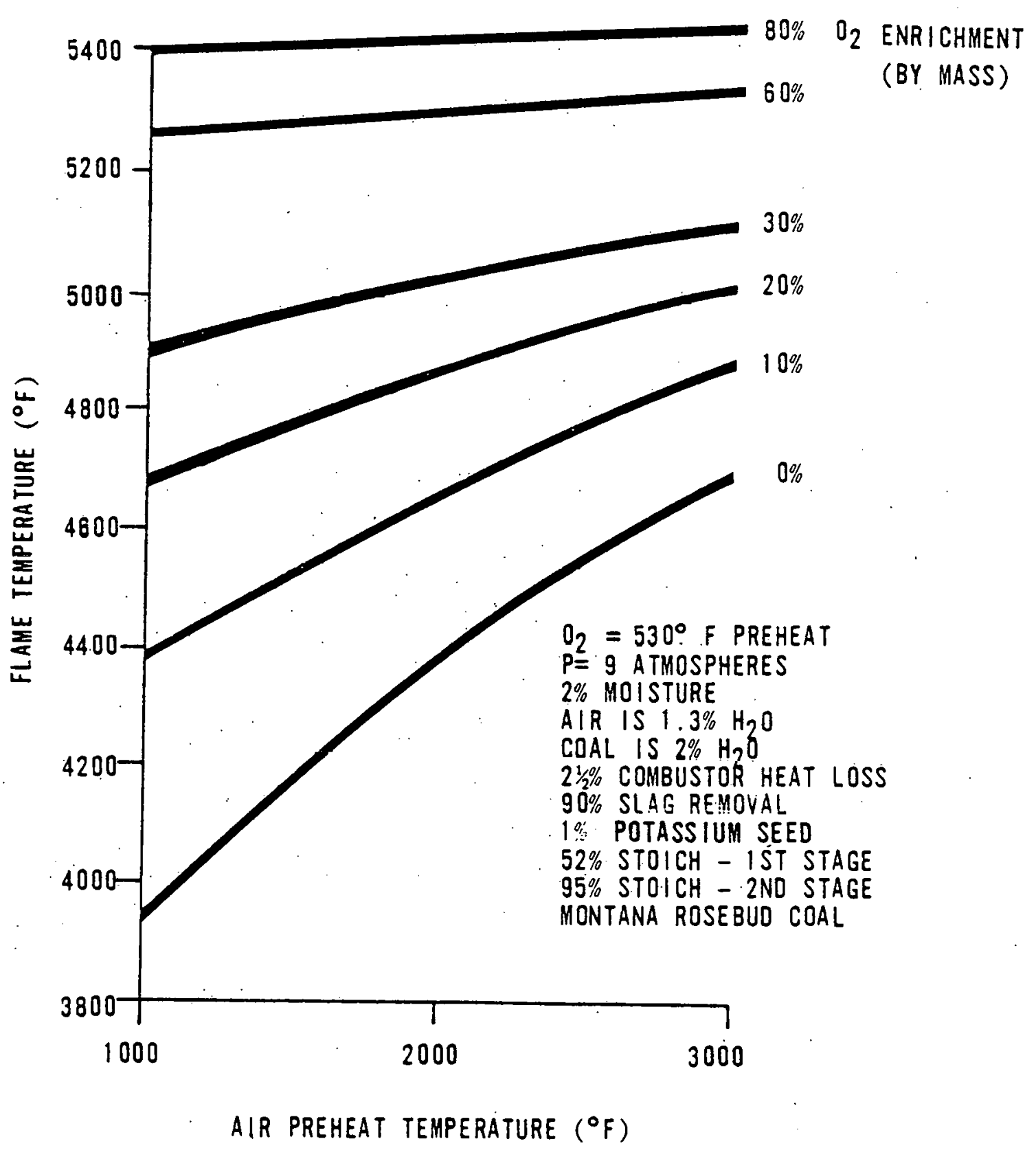


FIGURE 5-2

PLASMA ELECTRICAL CONDUCTIVITY VS. PLASMA TEMPERATURE

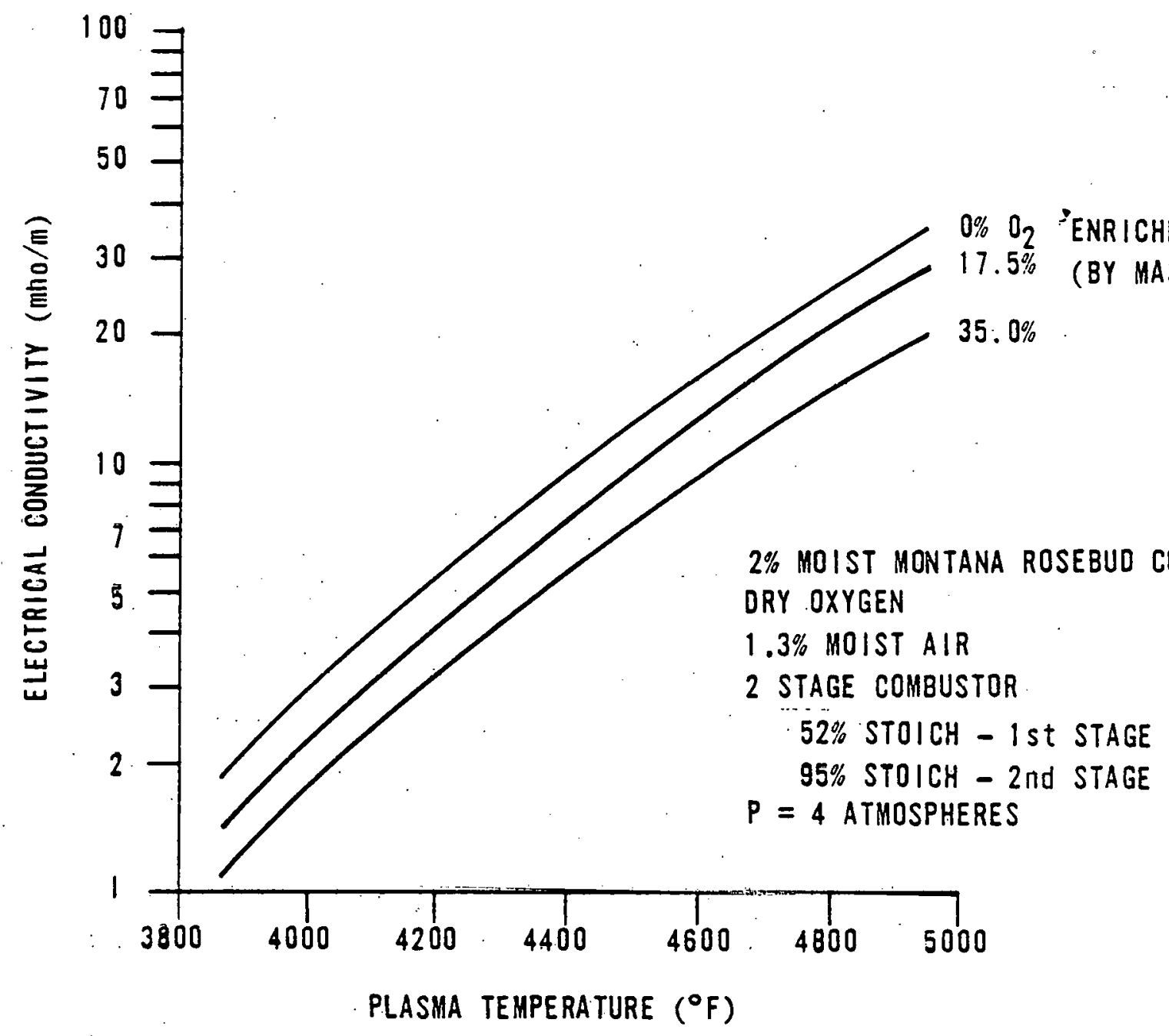




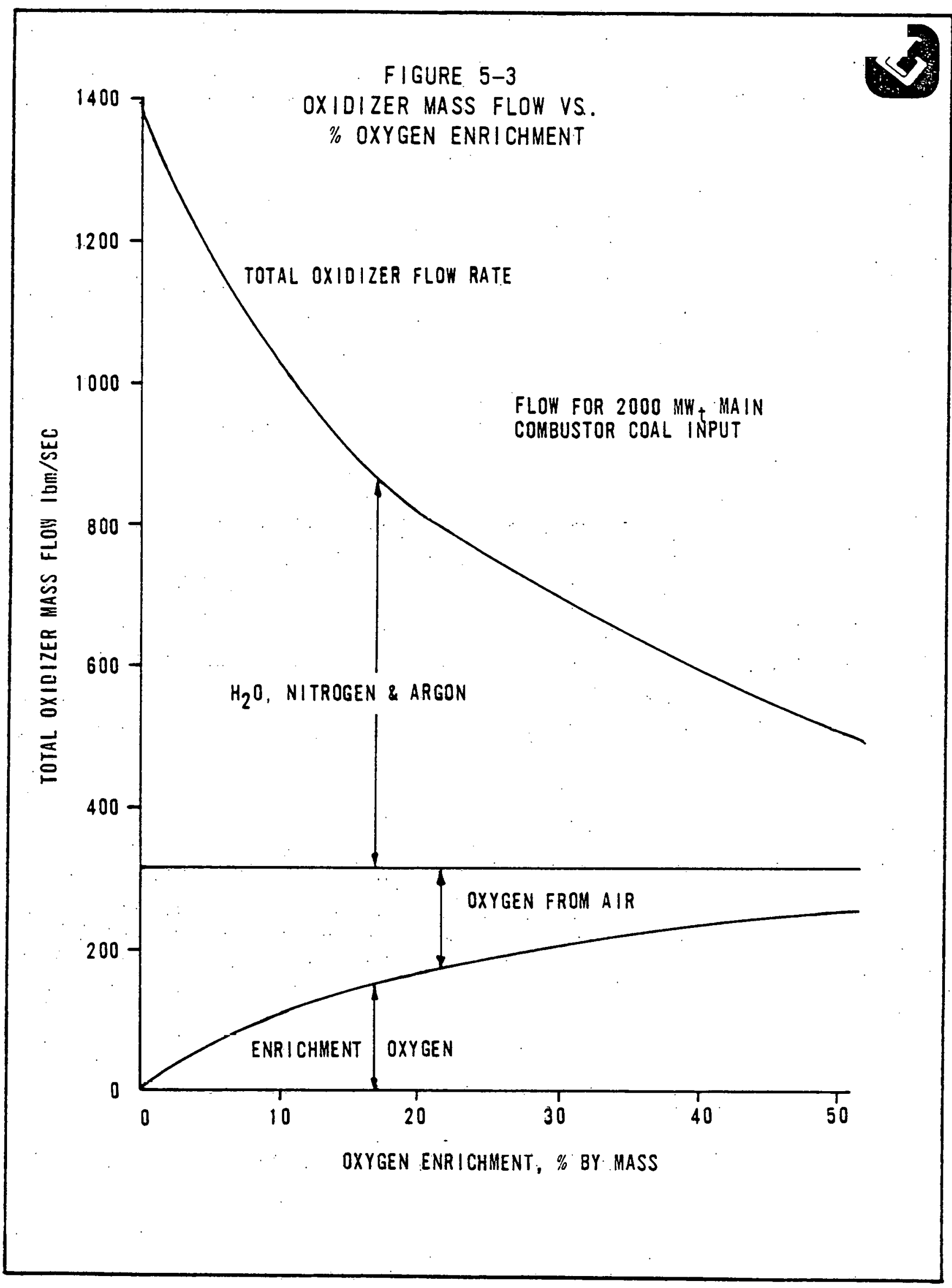


A preliminary analysis was conducted on the topping cycle to establish the effects of oxygen enrichment on the MHD components. Two oxidizer preheat temperatures of $1000^{\circ} \mathrm{F}$ and $2500^{\circ} \mathrm{F}$ were investigated and the general conclusions are:

- If constant channel $L / D$ and diffuser exit pressure are assumed, oxygen enrichment requires higher. combustor pressures.

- Mass flow rates through the system decrease as oxygen enrichment increases for a fixed amount of fue 1 .

- For a constant $L / D$ channel, the reduced mass flow will reduce the channel. length at a constant combustor pressure.

These preliminary topping cycle results were instrumental in guiding the analysis of the complete system that is presented in the remainder of Section 5.0.

\subsection{Bottoming System}

Although heat transfer to the cooling water in the channel and diffuser increases with oxygen enrichment, the total energy input to the steam bottoming cycle decreases due to the reduction in mass flow rate in the HRSR components. The optimum bottoming. cycle arrangement is being studied in depth by Gilbert/Commonwealth and will be discussed in a subsequent report on the effect of heat transfer on the bottoming cycle.

\subsection{System Performance}

In the preceding sections, the impact of oxygen enrichment on both the MHD topping cycle and the steam bottoming cycle was discussed. In this section, interim, results of a systems. analysis performed by Gilbert/ Commonwealth, which demonstrate the effect. of oxygen enrichment on overali plant efficiency, are presented. The systems analysis phase of this study is; however, not complete and only preliminary results obtained to date are discussed. 
A parametric analysis of the effect of oxygen enrichment on overall power plant performance of various preheat temperatures, MHD generator isentropic efficiencies, and oxygen production energies was performed to determine the potential of oxygen enriched MHO systems. Simplified schematic diagrams describing the separately fired and directly fired preheat systems used in this analysis are depicted in Figures 5-4 and 5-5. Note that three air and three oxygen compressor stages, each having two interstage coolers, have been considered to minimize the compressor power.

The effect of oxygen enrichment on overall power plant efficiency is shown in Figure 5-6. Using oxygen production power requirement as a parameter, channel lengths of 15, 25, and 35 meters were considered. These results are for a 2000 MWt plant with directly fired.high temperature air preheat of $2500^{\circ} \mathrm{F}$. An oxygen energy production requirement from 0 to $300 \mathrm{~kW}-\mathrm{hr} /$ ton was assumed, which brackets the expected values to be determined in the oxygen production study currently being performed by Gilbert/Commonwealth. The results indicate that if $2500^{\circ} \mathrm{F}$ preheat is available, oxygen enrichment does not offer a thermodynamic advantage.

Figure 5-7 and 5-8 show the relationship between combustor pressure, channel power generated, and diffuser exit temperature as a function of oxygen enrichment and channel length for a 2000 MWt plant with direct fired $2500^{\circ} \mathrm{F}$ air preheaters. In Figure 5-7, the power output from the MHD topping system reaches a maximum for a given channel length as the percent oxygen enrichment increases. Increased oxygen enrichment requires a higher combustor pressure for a fixed channel length. As the percent oxygen enrichment increases, the flame temperature and, therefore, the electrical conductivity of the combustion gas increases; however, the electrical conductivity also varies inversely with 


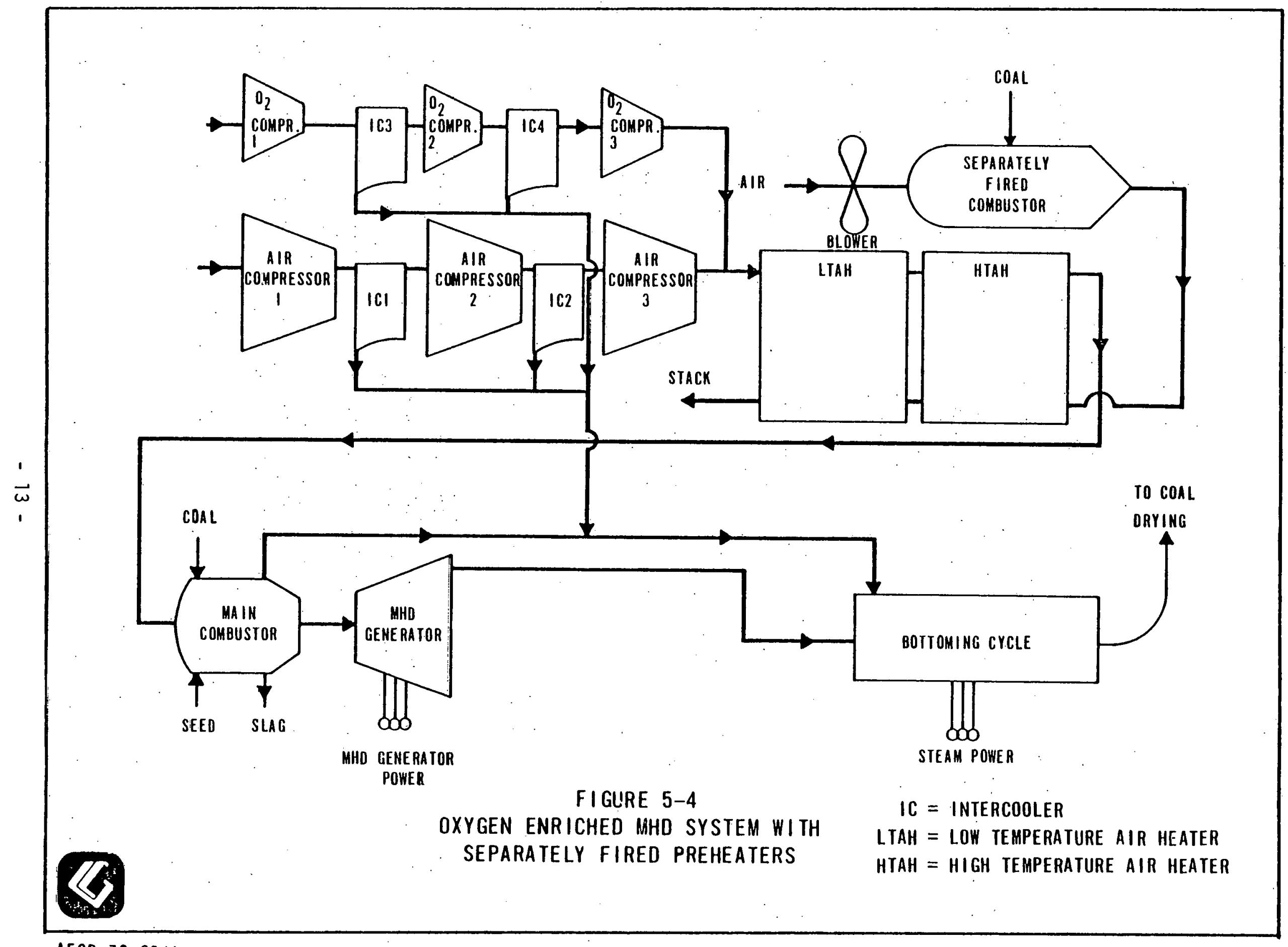




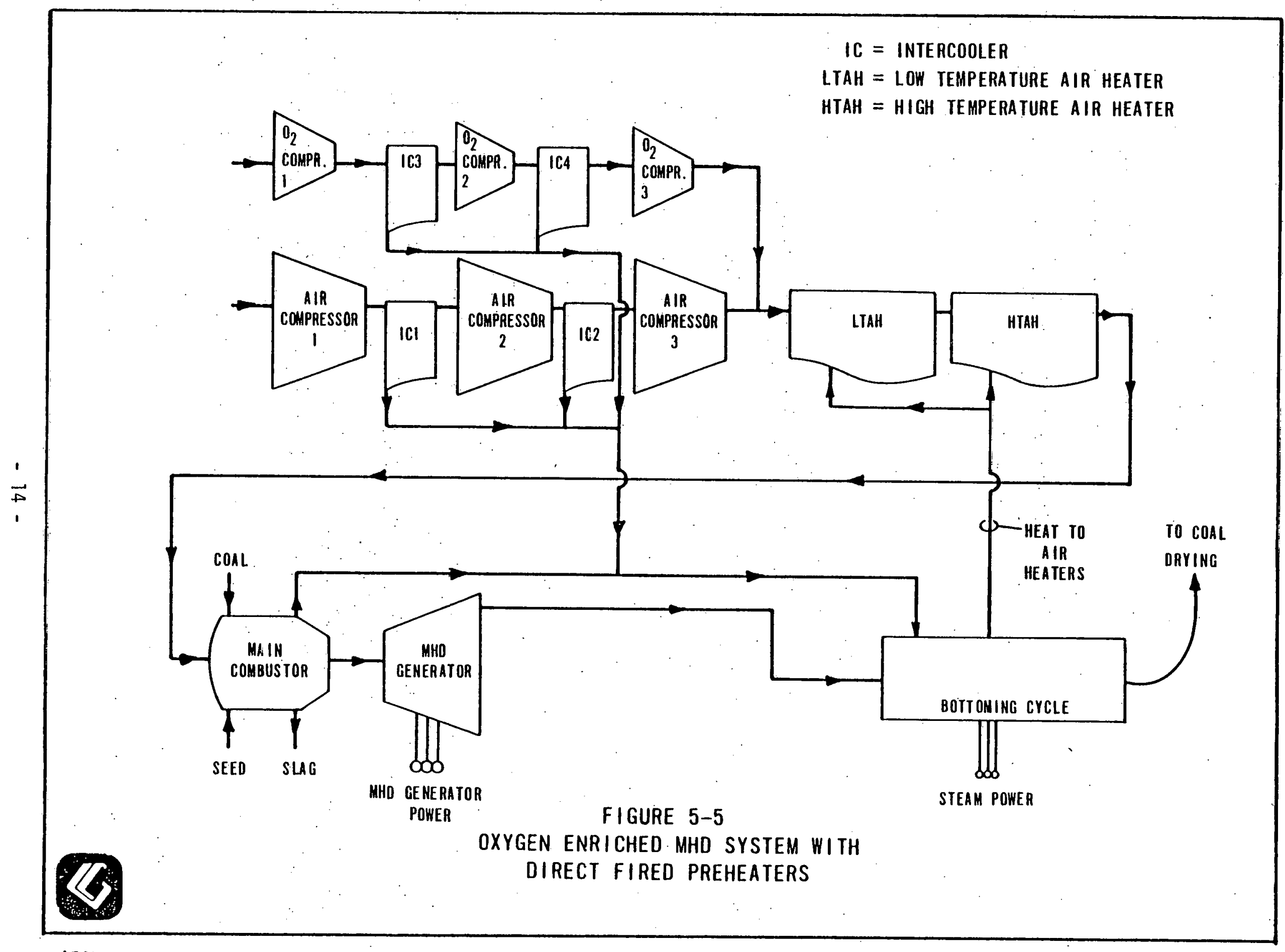




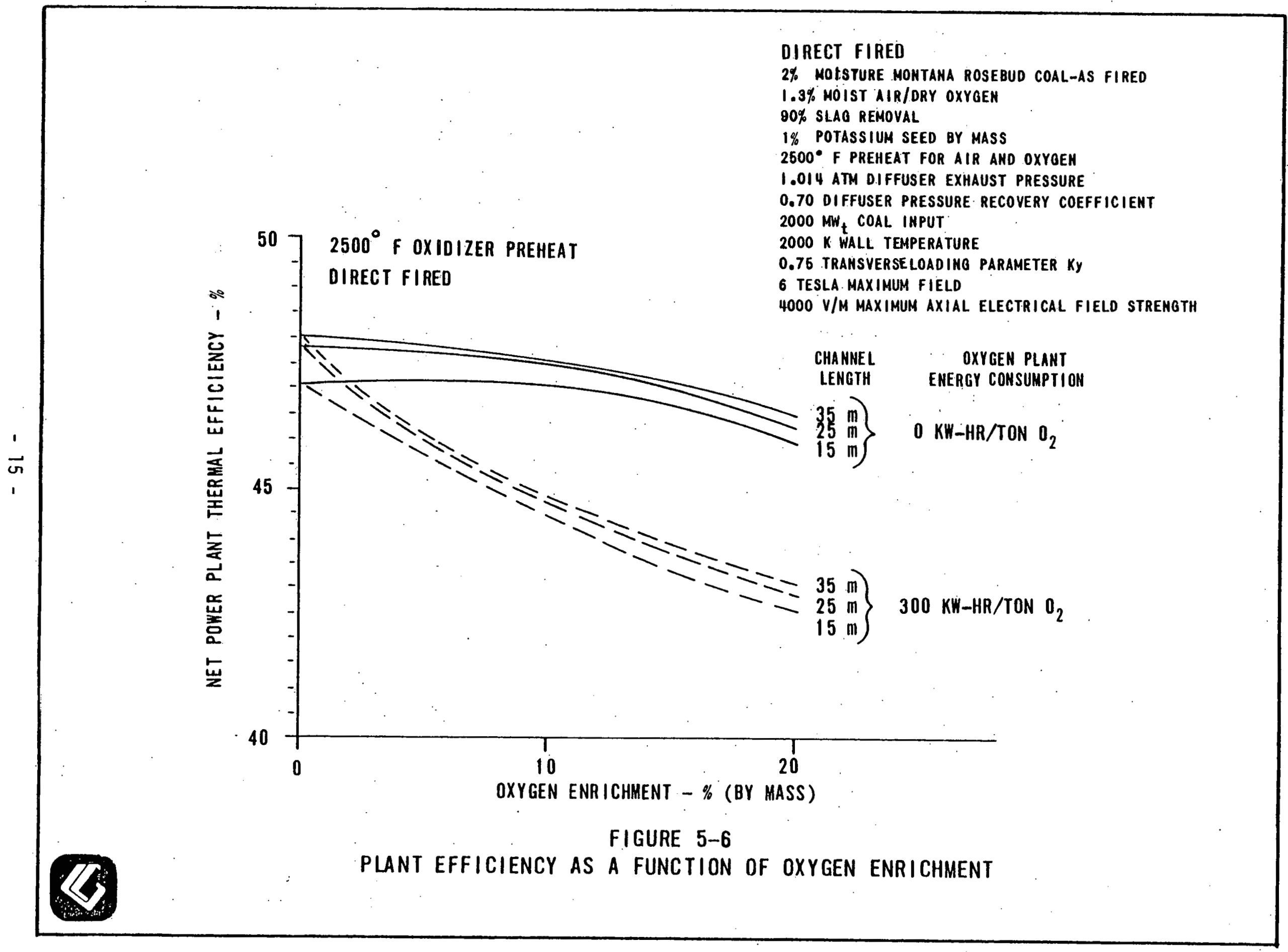




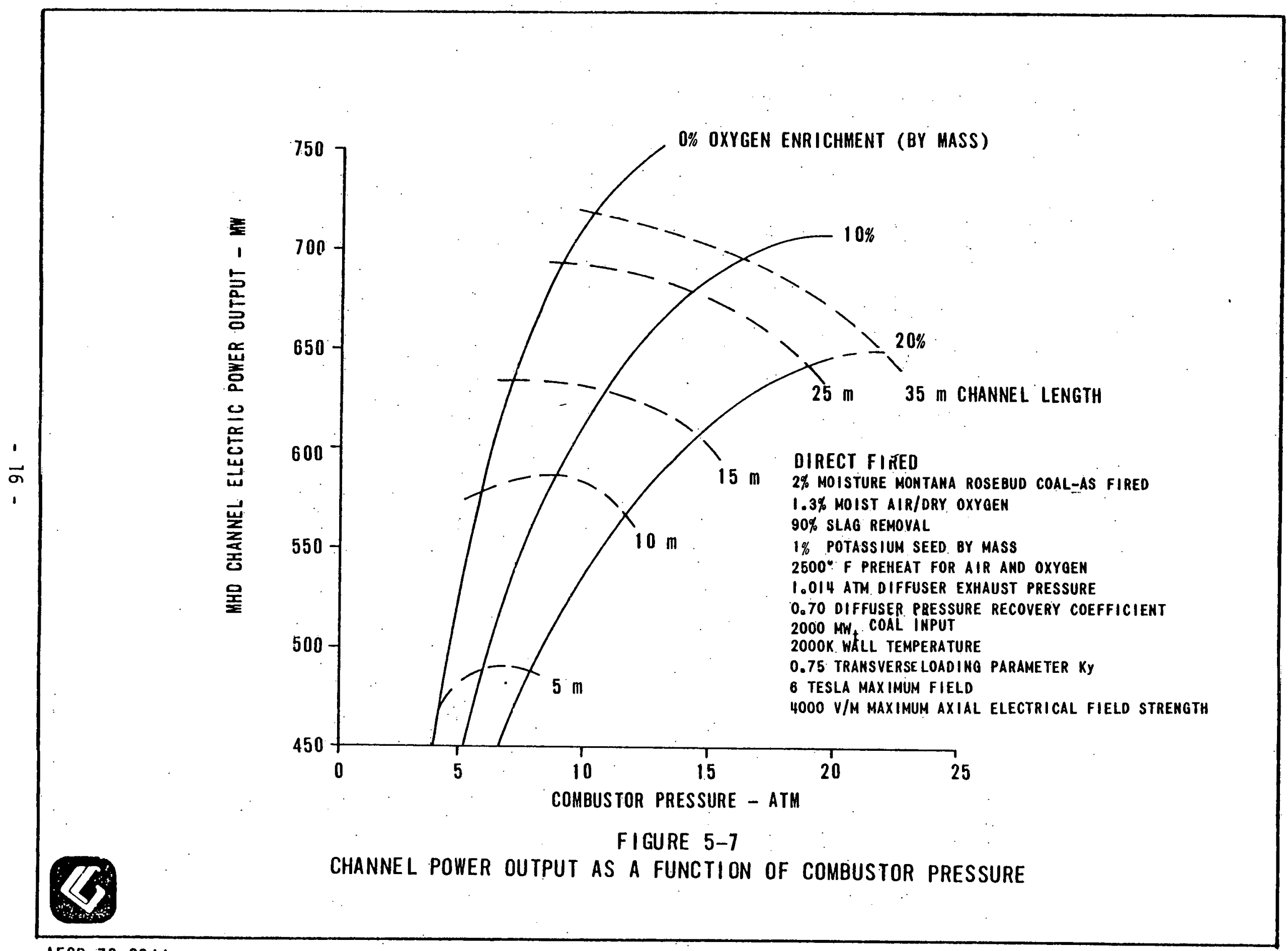




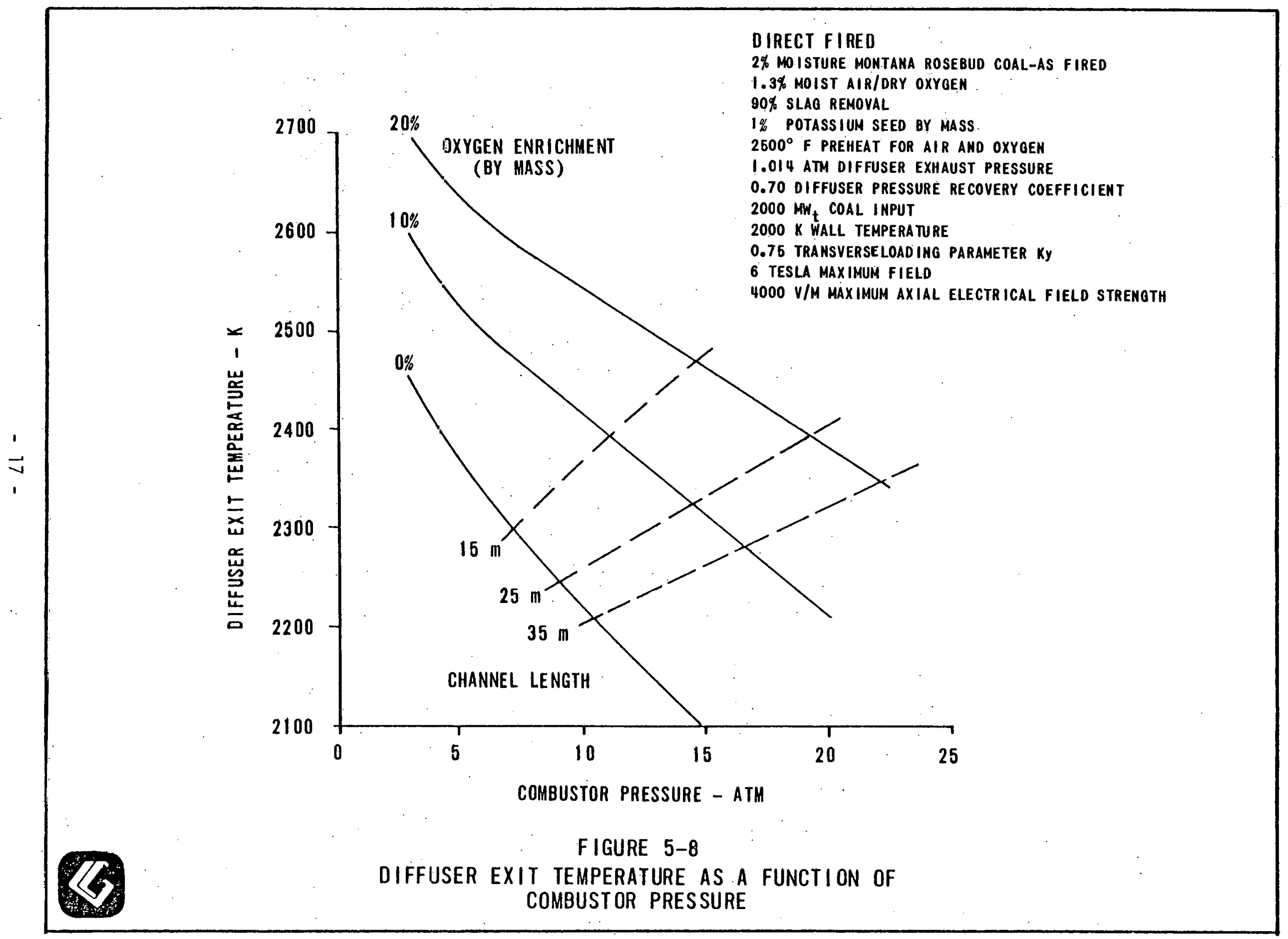


pressure. At high combustor pressure, electrical conductivity decreases more quickly as the effect of pressure becomes more significant than the increase due to higher flame temperature.

The diffuser exit temperature as a function of combustor pressure, oxygen enrichment and channel. length is shown in Figure 5-8. This figure shows that, as the percent oxygen enrichment increases for a given channel length, both the combustor pressure and the diffuser exit temperature must increase.

Figures 5-9 through 5-11 parametrically show ideal.relationships between plant efficiency and oxygen enrichment for a $2000 \mathrm{MW}_{t}$ plant with $2500^{\circ} \mathrm{F}$ directly and separately fired air preheaters. The diffuser exit pressure and temperature were held constant at $1.014 \mathrm{~atm}$ and $3750^{\circ} \mathrm{F}$ $\left(2339^{\circ} \mathrm{K}\right)$, respectively. The expansion efficiency was assumed constant at 70,85 , and $100 \%$. These curves represent idealized cycle performance potentials for the conditions illustrated, but do not represent actual MHD operating characteristics. The cycle pressure ratios, particularly at higher oxygen enrichments, are extremely high.

The Expansion Efficiency is defined as:

$$
\text { Expansion Efficiency }=\frac{\text { actual expansion } \Delta h}{\text { isentropic expansion } \Delta h}
$$

Where $\Delta h$ is the specific stagnation enthalpy change from combustor discharge to the expansion line end point. The expansions do not include heat loss during the expansion process; thus all of the energy released in the expansion is converted into electric power. Realistic bottoming systems and plant auxiliary losses have been incorporated into these net system performance estimates. 


\section{FIGURE 5-9}

PLANT EFFICIENCY AS A FUNCTION CF OXYGEN ENRICHMENT FOR 70\% EXPANSION EFFICIENCY

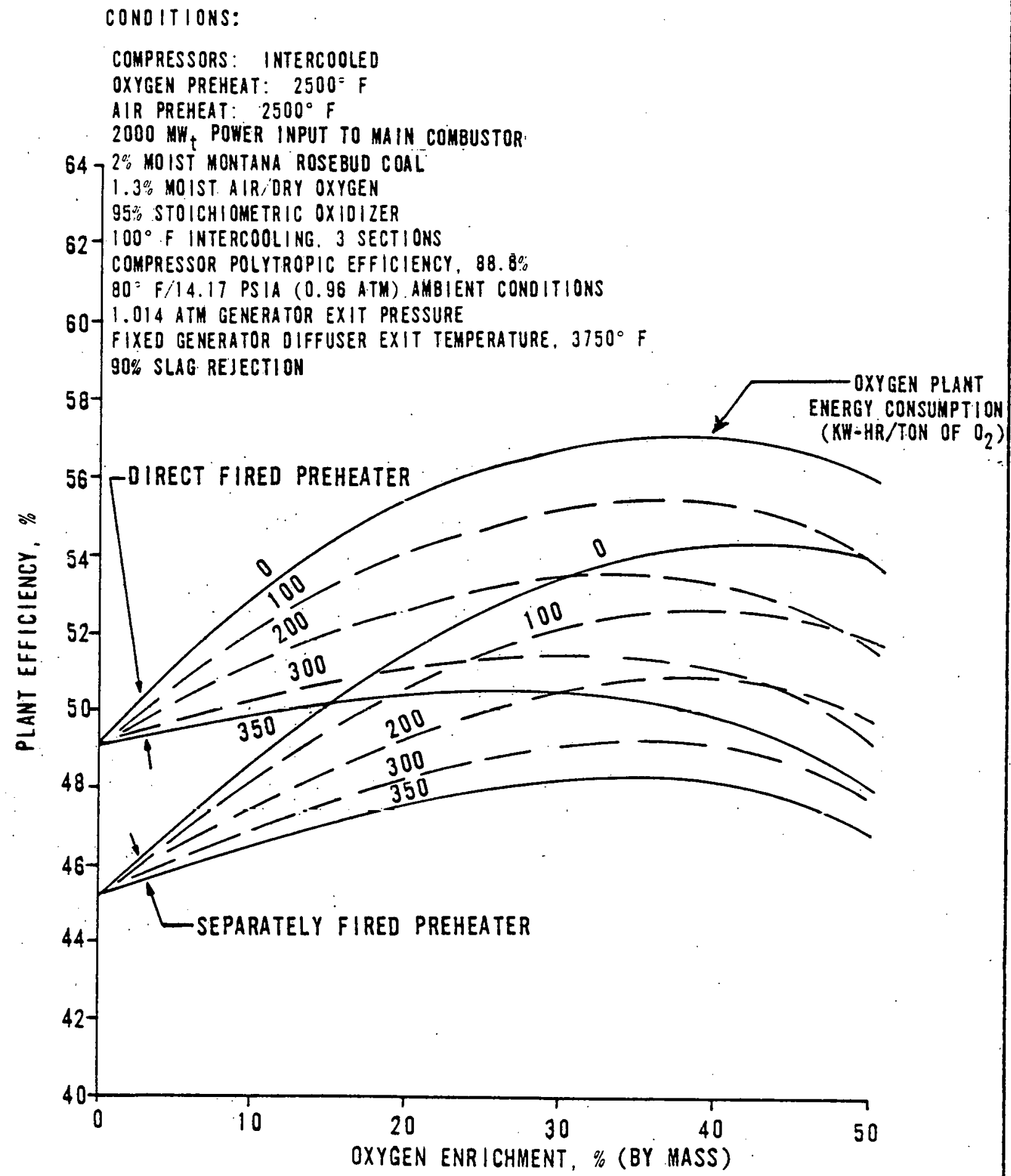




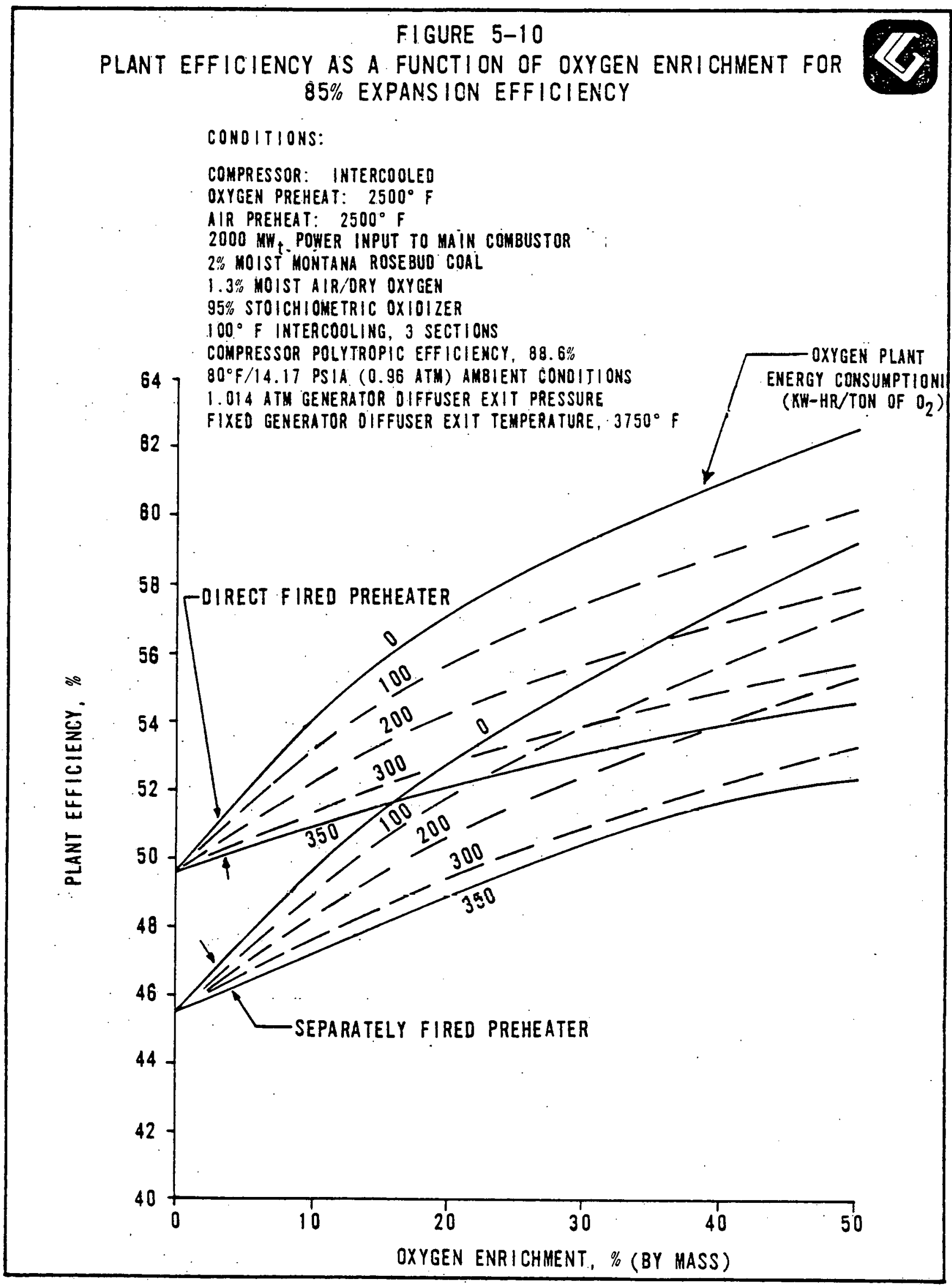




\section{FIGURE 5-11.}

\section{PLANT EFFICIENCY AS A FUNCTION OF OXYGEN ENRICHMENT FOR $100 \%$ EXPANSION EFFICIENCY}

\section{CONDITIONS:}

COMPRESSORS: INTERCOOLED

OXYGEN PREHEAT: $2500^{\circ} \mathrm{F}$

AIR PREHEAT: $2500^{\circ} \mathrm{F}$

FIXED GENERATOR OIFFUSER EXIT TEMPERATURE, $3750^{\circ} \mathrm{F}$

$2 \%$ MOIST MONTANA ROSEBUD COAL

1.3\% MOIST AIR/DRY OXYGEN

95\% STOICHIOMETRIC OX.IOIZER

$100^{\circ} \mathrm{F}$ INTERCOOLING, 3 SECTIONS

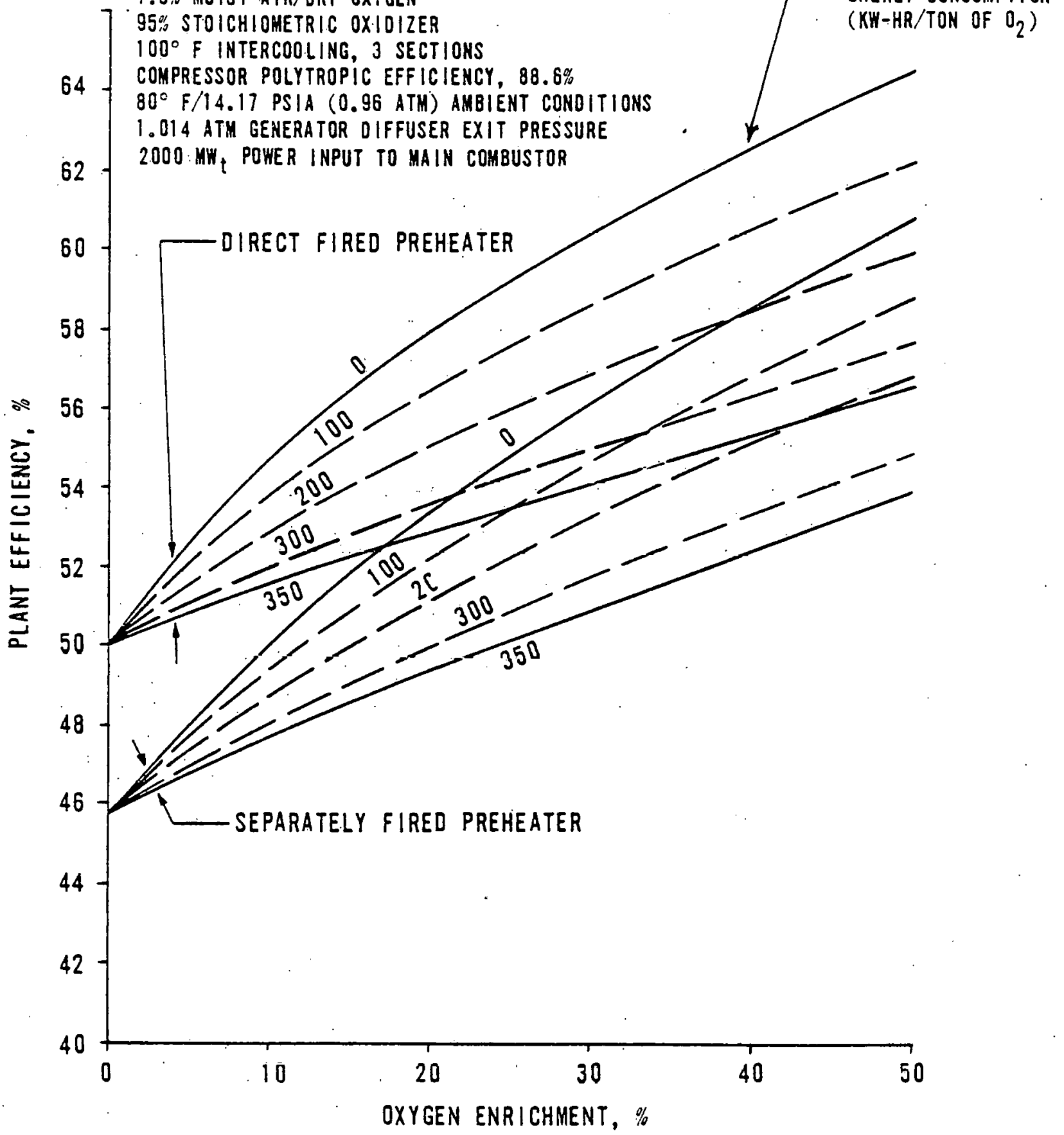




\subsection{ECONOMICS OF OXYGEN ENRICHMENT}

The economic implications of oxygen enrichment are currently being investigated by Gilbert/Commonwealth under a separate DOE/MHD study. In this study, the required oxygen production power requirements plus total operating costs and capital costs will be determined at several oxygen purity levels. Since the combustor pressure for MHD systems depends on the particular channel design. and system configuration; both air and oxygen compression levels are being investigated to achieve the required pressures for the enriched combustion air. Three air separation process cycles are being considered:

- Low pressure double column.

- Low pressure single column.

- Dual pressure split cycle.

This oxygen production study will identify the most viable processes for MHD combustor applications and will identify the applicable capital and operating cost.

\subsection{RESULTS OF STUDY}

\subsection{Conclusions}

Although the study of oxygen enrichment is still in progress, a number of interim conclusions can be drawn from the results achieved to date:

- Provided that high temperature air heaters are available for MHD plants and that temperatures in excess of $2500^{\circ} \mathrm{F}$ to $2700^{\circ} \mathrm{F}$ are obtainable, there is no thermodynamic or economic advantage to using an oxygen enriched system. 
- A low temperature metallic air heater with oxygen enrichment offers an alternative to the use of high temperature air heaters.

- Oxygen enrichment can be used to supplement high temperature air heaters for preliminary testing of components, as an alternative system in the event of a total or partial failure of the high temperature air heater system, or to provide minimal adjustments to the channel power output for load following.

o. Oxygen enrichment lowers the combustion gas electrical conductivity when compared to an air only system at the same pressure and temperature.

- The total mass flow rate of the combustion gases is lower for an oxygen enriched system than with pure air. Reduced mass flow rates can result in smaller component size.

- An oxygen enriched system requires a higher pressure ratio to maintain the same $L / D$ and diffuser exit pressure compared to a system using pure air.

- The heat loss in the MHD channel is larger for oxygen enriched systems compared to calculations assuming air as the oxidant.

- An oxygen enriched system may result in a favorable reduction of ${ }^{\mathrm{NO}}{ }_{\mathrm{x}}$.

\subsection{Recommendations For Further Study}

This Interim Report should be expanded in subsequent studies by incorporation of the following discussions and study results:

- The results from the oxygen production study which will identify the required oxygen production power consumption, operating cost, and capital cost of alternate oxygen production plants.

- The optimum bottoming cycle arrangement should be included with studies of an oxygen enriched MHD plant.

- The formation of NO in an oxygen enriched plant is expected to be less than that predicted for a plant using only air as an oxident. This conclusion will be analytically verified and the results included in subsequent work. 
- Pertinent information from the Gilbert/Commonwealth study on separately fired preheaters currently in progress should be incorporated. in future work. The influence of oxygen enrichment on preheater performance is being considered as part of the preheater analysis.

- Oxygen enrichment is also being considered in a study being performed by Gilbert/Commonwealth for DOE/MHD on power output variations for intermediate and peaking duty. This study will determine the feasibility of using oxygen enrichment to increase the baseload MHD channel. power output level in order to satisfy intermediate and/or peaking duty demands. These parametric results should be included in future work.

- Future work should include the effect of oxygen enrichment on cost of electricity (COE) and capital cost for a fully integrated, oxygen enriched MHD power plant. Included in the COE will be the cost associated with the seed. The seed fraction, which was defined as one percent of the total mass flow from the combustor, was held constant in the results presented in this Interim Report. As noted, oxygen enrichment reduced the total mass flow rate and, therefore, the mass flow rate of seed was correspondingly reduced, which effects the COE. Performance results should be determined with oxygen enrichment for a constant seed mass flow rate.

- The subsonic channel results presented in this Interim Report should be extended to inciude the effect of oxygen enrichment on supersonic channel performance.

- In future work, the influence of oxygen enrichment on individual component design should be discussed. Component design may differ significantly due to mass flow rate, thermal properties and temperature levels expected with oxygen enrichment. 


\subsection{REFERENCES}

1. Gordon, S. and McBride, B. J.: "Computer Program for Calculation of Complex Chemical Equilibrium Compositions, Rocket Performance, Incident and Reflected Shocks, and Chapman-Jouget Detonations"; NASA/Lewis Research Center, NASA SP-273; 1971.

2. Addington, J. H., Peabody Coal Company: Letter to D. C. Burton, Gilbert Associates, Inc. ; November 21, 1977.

3. Anon: "JANAS Thermochemical Data-Series E;" Dow Chemical Company; Midland, Michigan; January 1967.

Note

Additional references in. Appendix $A$ are listed at the end of that appendix. 
APPENDIX A

OXYGEN ENRICHMENT EFFECTS ON MHD

CHANNEL PERFORMANCE

LITERATURE SURVEY

$A-1$ 


\section{PREVIOUS STUDIES}

The studies referenced in this appendix and reviewed for the preparation of this report are concerned primarily with MHD cycle efficiency and overall plant performance. The effects of oxygen enrichment on MHO plant component availability and maintainability, as well as oxygen production techniques and costs, are currently under study and findings will be published separately.

Throughout this report, values of oxygen enrichment are quoted as percent by mass, which is defined as the mass of oxygen added divided by the mass of oxygen added plus the mass of air. Other definitions for oxygen enrichment are found in the literature; however, for consistency, all values have been converted to conform with this definition.

One of the first investigations of MHD system performance with oxygen enrichment was reported by Heywood and Womack (Reference 1 ). Their work was based on extensive analytical and experimental research, performed in England in the 1960's, which indicated that overall cycle efficiency decreases with increasing oxygen enrichment. This decrease in efficiency with oxygen enrichment was. attributed to the reduced mass flow rate through the channel for a constant thermal input. Results of the Heywood and Womack effort are presented in Figures A-I through A-4.

Figure A-I shows the electrical power output from an MHD generator as a function of the channel inlet stagnation pressure for a $1000 \mathrm{MWt}$ coal-fired plant. Curves 1 and 2 compare the air-fired case with an $18 \%$ (by mass) oxygen enriched case. The following conclusions can be derived from this curve:

- The air-fired case has a higher generator power output for the inlet temperatures and pressures shown, even though the flame: temperature is lower $\left(4580^{\circ} \mathrm{F}\right)$ for air than the oxygen enriched case $\left(4940^{\circ} \mathrm{F}\right)$. Heywood and Womack attributed this to the reduction of mass flow with oxygen enrichment. 


\section{FIGURE $A-1$}

MHD POWER OUTPUT AS A FUNCTIION OF

CHANNEL INLET PRESSURE FOR A $1000 \mathrm{MW}_{\mathrm{t}}$ PLANT (FROM REF. 1)
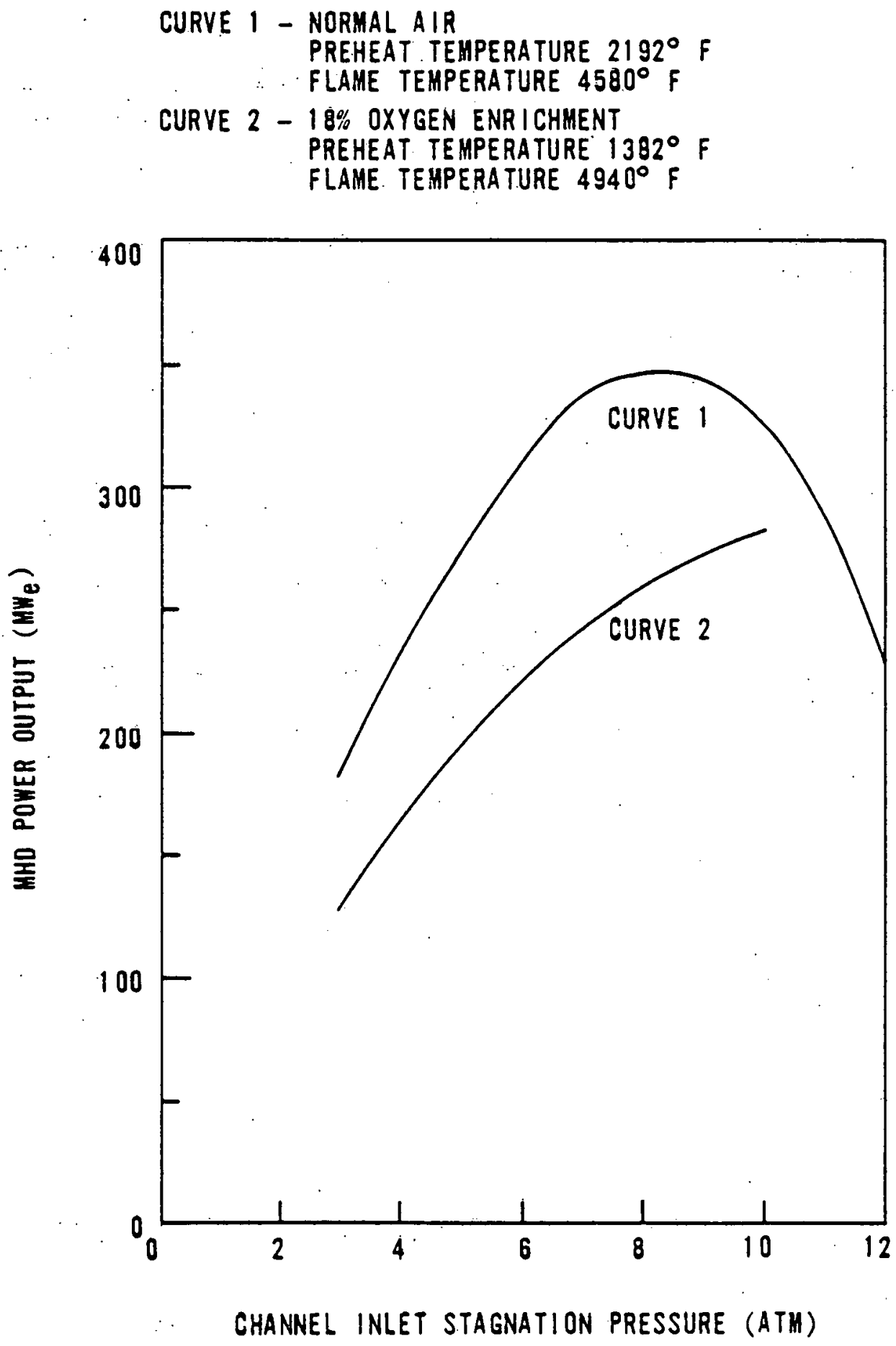
- Curve 1 shows the existence of an optimum pressure ratio for a given set of conditions. MHD power output increases with inlet pressure until the effect of electrical conductivity (which is inversely proportional to the square root of the pressure) becomes pronounced and further pressure increases cause a decline in power output.

- A higher pressure ratio is required to attain an optimum power output when using oxygen enriched air.

Figures $A-2, A-3$, and $A-4$ show the effect of oxygen enrichment on plant efficiency as a function of channel length, preheat temperature and the power required to operate the oxygen production plant.

- Figure A-2 indicates that pure air oxidizer has a higher plant efficiency (almost $46 \%$ ) than either the $5.6 \%$ or $17 \%$ oxygen enriched cases.

- For a fixed inlet stagnation pressure, channel length is shorter with increasing oxygen enrichment (Figure $A-2$ ).

- A comparison of Figures $A-2$ and $A-3$ shows the effect of oxygen production power on overall plant efficiency. At the lower cost (Figure A-4), which is close to the value predicted in a recent study using the Lotepro oxygen production method, plant efficiency is approximately the same as predicted for pure air. Higher oxygen production costs lower the overall power plant efficiency.

- Figures $A-3$ and $A-4$ show the effect of lowering preheat temperature while maintaining constant oxygen production power requirements. As can be seen, with decreased preheat temperature, oxygen enrichment results in a higher overall plant efficiency when compared with pure air.

- From Figures $A-3$ and $A-4$, it can be seen that at a given level of oxygen enrichment, as preheat temperature decreases, plant efficiency also decreases. Figure A-3 indicates a plant efficiency of almost $46 \%$ with pure air preheated to $2192 \mathrm{~F}$ compared to approximately $43 \%$ plant efficiency (Figure A-4) with a preheat temperature of $1832^{\circ} \mathrm{F}$.

In summary, the results reported by Heywood and Womack indicate that, with sufficient levels of preheat temperature, plant efficiency is higher with pure air than with oxygen enrichment. This conclusion 
FI GURE A-2

PLANT EFFICIENCY AS A FUNCTION OF CHANNEL LENGTH (REF.. 1.) PREHEAT TEMPERATURE $2192^{\circ} \mathrm{F}$ OXYGEN PLANT POWER REQUIRED $330 \mathrm{~kW}$-HR/TON

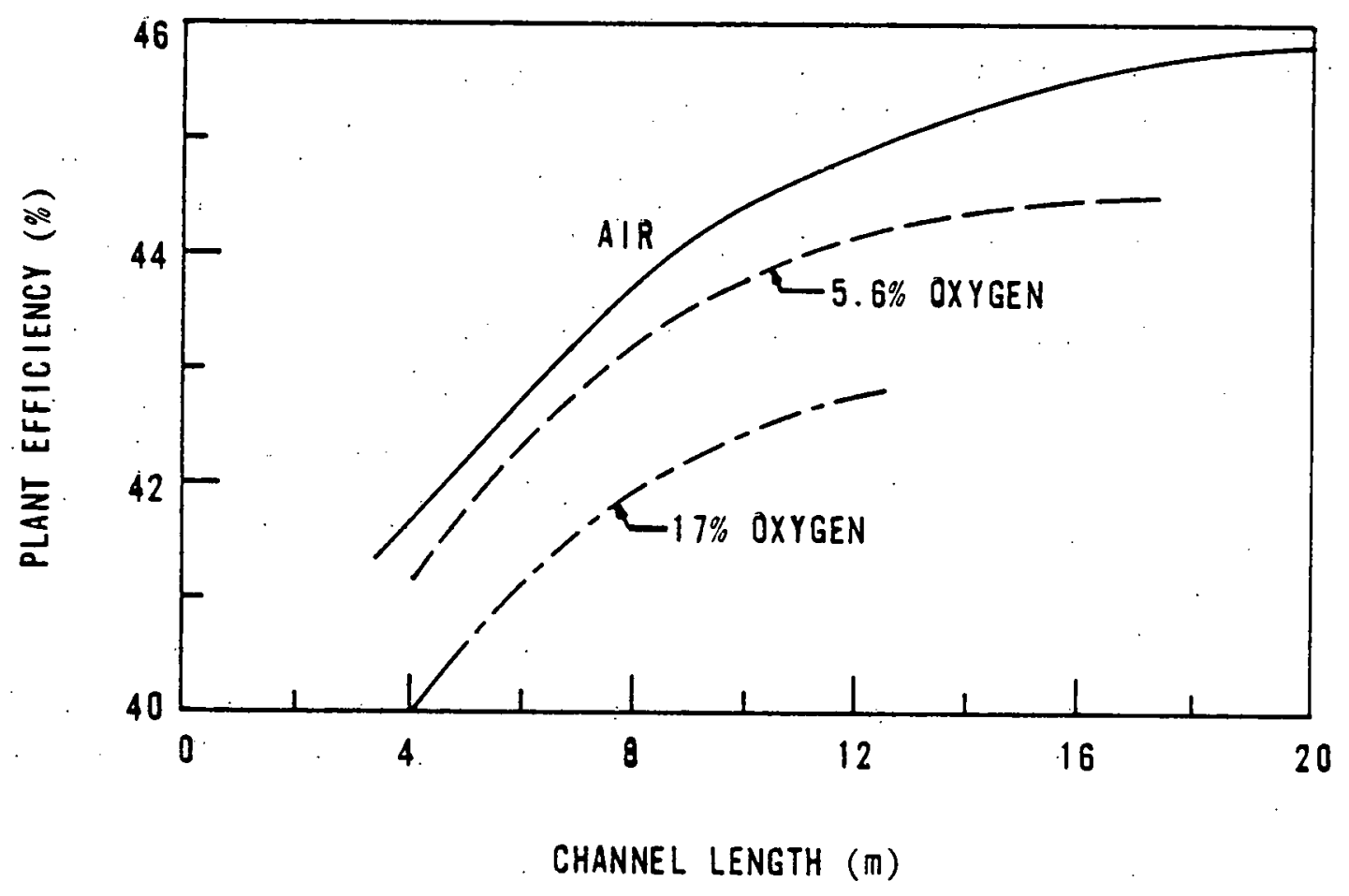


FIGURE A-3

PLANT EFFICIENCY AS A FUNCTION CF CHANNEL LENGTH. (REF. 1)

PREHEAT TEMPERATURE $2192^{\circ} \mathrm{F}$ OXYGEN PLANT POWER REQUIRED $178 \mathrm{KH}-\mathrm{HR} / \mathrm{TON}$

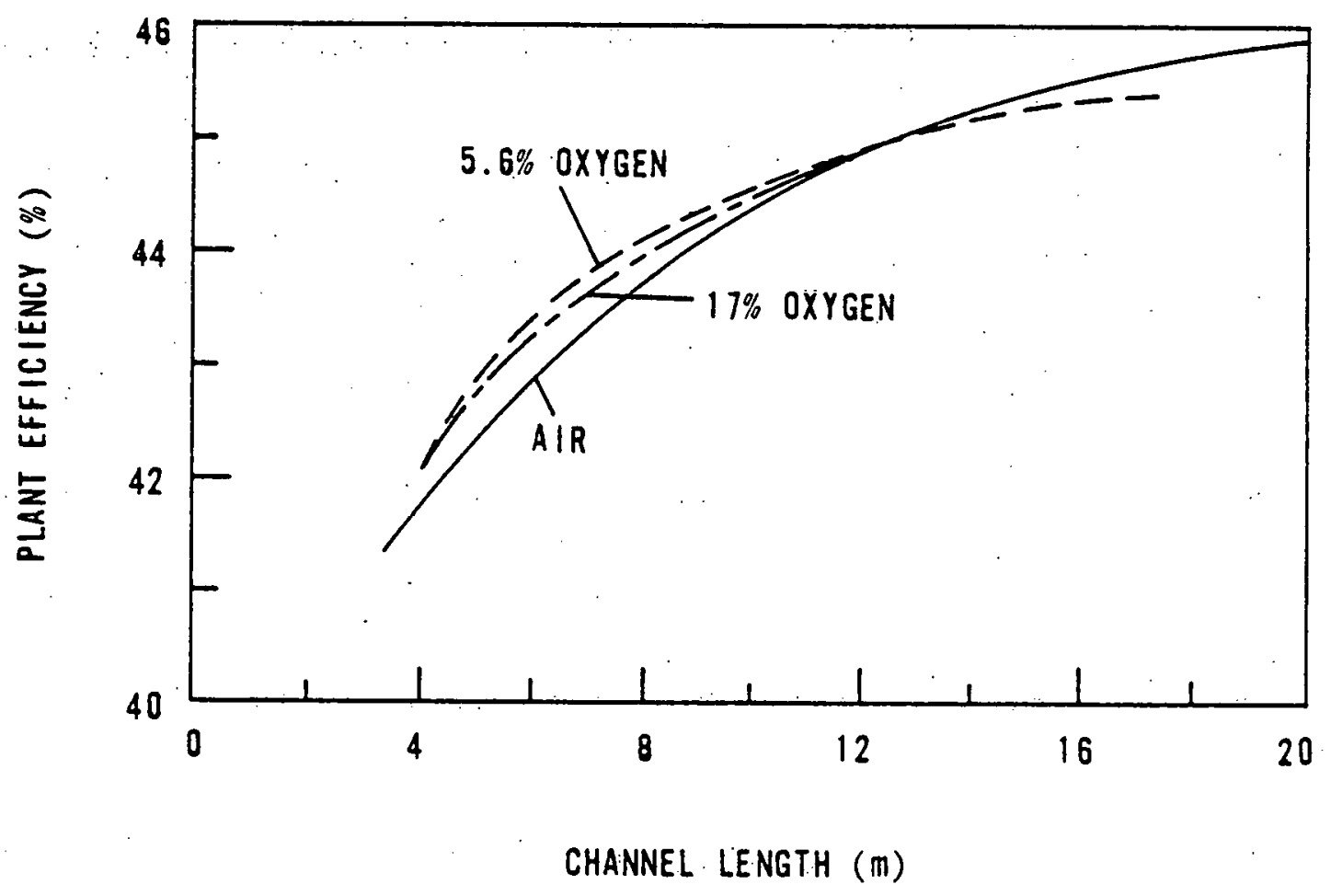


FIGURE A-4

PLANT EFFICIENCY AS A FUNCTION OF CHANNEL LENGTH (REF.. 1) PREHEAT TEMPERATURE $1832^{\circ} \mathrm{F}$

OXYGEN PLANT POWER REQUIRED $178 \mathrm{KW}-\mathrm{HR} / T O N$

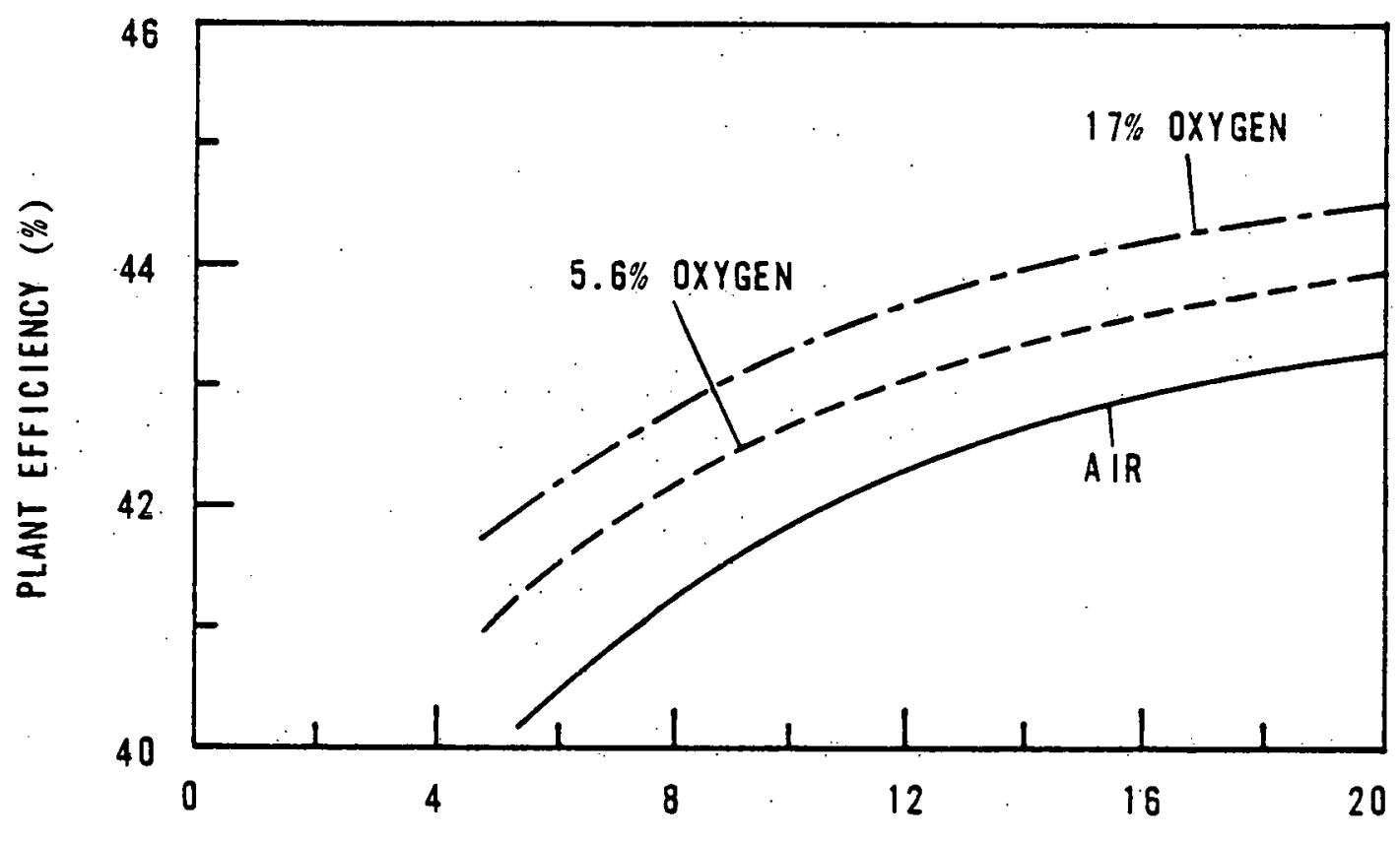

CHANNEL LENGTH (m) 
is particularly pronounced at higher oxygen production power requirements. At lower preheat temperatures, oxygen enrichment becomes more beneficial. Heywood and Womack stated that "Although the preheater costs will be significantly reduced as the preheat temperature is lowered, its reduction will not balance the cost of the oxygen plant. For these reasons, oxygen enrichment has not been studied further" (by Heywood and Womack).

Bergman, et al., (Reference 2) indicate that MHD systems incorporating directly fired, high temperature air preheaters are economically and thermodynamically superior to oxygen enriched systems. Calculations performed for oxygen enrichment up to $9 \%$ by mass at a preheat temperature of $1500^{\circ} \mathrm{F}$ indicated a cycle efficiency of $36.4 \%$ as compared to $44.4 \%$ for air preheated to $2200^{\circ}$. F. Reduced mass flow rate and higher fractional heat loss in the MHD generator were stated in Reference 2 as the reasons for the decrease in performance with oxygen enrichment. The enthalpy extraction ratio decreased from $18.0 \%$ with air to $15.3 \%$ with $9 \%$ oxygen enrichment. Sufficient information for a detailed comparison between the two cases was not reported. The power required for oxygen production was not included in these calculations. The authors estimated that, with oxygen power requirements included, the plant efficiency with oxygen enrichment would be below $34 \%$.

The Energy Conversion Alternatives Study (ECAS) (Reference 3) compared a directly fired, air preheat $\left(2500^{\circ} \mathrm{F}\right)$ cycle to a $17 \%$ by mass oxygen enriched, separately fired $\left(1500^{\circ} \mathrm{F}\right)$. preheat cycle. The cycle efficiencies and cost of electricity were $48.3 \%$ and $43.9 \mathrm{mill} / \mathrm{s} / \mathrm{kW}-\mathrm{hr}$ for the directly fired air cycle and $43.3 \%$ and $47.9 \mathrm{mills} / \mathrm{kW}-\mathrm{hr}$. for the oxygen enriched, separately fired cycle. The ECAS results indicate that oxygen enrichment. with. low temperature preheat can be a relatively straight forward method of obtaining competitive costs of electricity for open cycle MHD systems. Although low temperature preheat and oxygen 
enrichment give lower cycle efficiency and thus a higher cost of electricity, the simplified plant layout and: piping result in lower capital cost.

The performance potential of alternate open cycle MHD power plant configurations was reported by Seikel, et al., (Reference 4). Based on GE/AVCO Phase I and Phase II ECAS results, realistic values of the overall efficiency (coal pile to bus bar) are $43 \%$ for an oxygen enriched MHD plant with low temperature preheat $\left(1300^{\circ} \mathrm{F}\right.$ ) and $50 \%$ for a directly fired MHD plant with high temperature preheat $\left(2500^{\circ} \mathrm{F}\right)$ without oxygen enrichment. ECAS studies indicated that metallic recuperative lowtemperature preheaters may be limited to preheat temperatures on the order of $1300^{\circ} \mathrm{F}$; and that $1500^{\circ} \mathrm{F}$.might be an upper limit. Thus, for recuperative preheating only, oxygen, enrichment will be a necessity. The plants studied in. ECAS were not optimized and it is difficult to assess the effects of optimization without additional detailed studies.

AVCO considered oxygen enrichment of up to $33.3 \%$ by volume ( $17 \%$ by mass) for a directly fired preheat cycle. Table A-I shows comparable information on AVCO's analyses (Reference 5) of preheated normal and oxygen enriched air. Air preheated to $2000^{\circ} \mathrm{F}$ and $3000^{\circ} \mathrm{F}$, with 5.5 atm and 14 atm combustor pressures, resulted in net plant efficiencies of 50.5 and 59.7\%, respectively. Oxygen enriched air preheated to $1500^{\circ} \mathrm{F}$ at a pressure of 16 atm had an efficiency of $49.2 \%$. AVCO concluded that "From a thermodynamic viewpoint, the optimum degree of oxygen enrichment decreases with increasing preheat temperature; therefore, at a high preheat temperature there is. no thermodynamic advantage in the use of oxygen. However, at a more moderate preheat temperature, attainable with tubular metal alloy heat exchangers of conventional type, the use of oxygen might be considered for central station power plant applications." 
TABLE A-I

Summary of AVCO Data (Reference 5)

Preheat Temperature $-{ }^{\circ} \mathrm{F}$

$\underline{2000 \quad 3000 \quad 1500}$

Oxidizer

Air . Air. Air plus oxygen*

Burner

Pressure (atm)

5.5

14

16

Energy Balance

MHD Power (Gross)(MW)

$590 \quad 990 \quad 690$

Steam Power Gross)(MW)

$610 \quad 462 \quad 575$

Total (MW)

$1200 \cdot 1452 \quad 1265$

Compressor Power (MW)

$157 \quad 220$

173

Plant Aux. \& Inverter Losses (MW)

42

38

43

Total (MW)

199

258

281

Net Plant Output (MW)

1001

1194

984

Net Plant Efficiency (\%)

50.0

59.7

49.2

*oxygen enrichment to $33-1 / 3 \%$ by volume ( $17 \%$ by mass) 
Westinghouse (Reference 6) performed a series of analyses for the Electric Power Research Institute (EPRI) in which the performance of an MHD plant combined with an integrated oxygen plant was evaluated as a function of pressure ratio, air preheat temperature and oxygen preheat temperature. These results were obtained with an oxygen enrichment of $17 \%$ by mass. The highest cycle efficiency observed was $42.5 \%$ with a preheat temperature of $1520^{\circ} \mathrm{F}$. A direct comparison of this plant with a similar plant having a high temperature air heater was not presented.

In a second EPRI study performed by Westinghouse on alternate configurations (Reference 7), cycle efficiencies on the order of $47.5 \%$ for a directly fired 1000 MWe plant and $41.5 \%$ for an oxygen enriched 500 MWe plant were obtained. Both plants burned high sulfur Illinois No. 6.coal. A major difference between the plants was that the oxygen enriched case considered seed regeneration and elemental sulfur recovery while the $2500^{\circ} \mathrm{F}$ preheated air cycle had scrubbers. Since accurate estimates of energy requirements for seed regeneration are presently not we 11 defined, an exact comparison between these cases was not made.

A study (Reference 8) performed in the Soviet Union encourages the use of oxygen enrichment based on optimum MHO generator characteristics. The authors state that substantial oxygen enrichment is desirable to increase MHD power plant efficiency, decrease magnet size, and reduce air pollution. Optimum oxygen enrichment was based on constant magnet size (and cost) and the maximum excess power provided by the MHD generator over the power required for axygen produrtion. 
1. Heywood, J. B., Womack, G. J.: "Open-Cycle MHD Power Generation;" Pergamon Press, Oxford; 1969.

2. Bergman, P. D., Plants, K. D., Joubert, J. I., Bienstock, D.: "Conceptual Design and Economics of an MHD Pilot Plant;" InterSociety Conference on Energy Conversion; Newark, Delaware; August 1975 ; p. 513-523.

3. "Energy Conversion Alternatives Study (ECAS) Summary Report"; NASA TM-7381; September 1977.

4. Seikel, G. R., Sovie, R. J., Barna, G. J., Burkhardt, J. A., Maininger, J. J., Smith, J. M., NASA-Lewis: "A Summary of the ECAS Performance and Cost Results for MHD Systems"; 15th Symposium $=-$-Engineering Aspects of Magnetohydrodynamics; Philadelphia -University of Pennsylvania; May 24-26, 1976.

5. Hals, F. J., Gannon, R. E.: "Development and Design Characteristics of Auxiliary MHD Power Plant Components"; ASME Paper 73-WA/EWER-10, ASME Winter Annual Meeting; Detroit, Michigan; November 1973.

6. Retallick, F. D., Westinghouse: Letter to J. J. Lynch, September 22, 1977, re EPRI/Westinghouse MHD Study Work on (1) A Separately Fired Preheater MHD System and (2) An Integrated MHO oxygen Plant.

7. Westinghouse $R \&$ D Center. "Operational Analysis of Open Cycle MHD." Interim Technical Report; February 1976 to June 1977. Pittsburgh, PA for EPRI. Research Project 639-1. 
8. Ivanov, P. P., Koryagina, G. M., Kovbasyak, : V. I., Shumyatsky, B.Ya., Institute for High Temperatures of the Academy of Sciences, Moscow, U.S.S.R.; "Analysis. of the Thermal Efficiency of an OpenCycle Power Installation Based on Generalized Diagram of the MHD Generator Characteristics"; Sixth International Conference on MHD Electrical Power Generation; Washington, D.C.; June 9-13, 1975 - Vol. VII, Vol I. 
APPENDIX B

\section{COMBUSTION GAS PROPERTIES}

$B-1$ 
APPENDIX B

Figure

$B-1$

B-2

$B-3$

B-4
Title

Combustion Products Mollier Diagram with 0\% Oxygen Enrichment (By Mass)

Combustion Products Mollier Diagram with 10\% Oxygen Enrichment (By Mass)

Combustion Products Mollier Diagram with 20\% Oxygen Enrichment (By Mass)

Combustion Products Mollier Diagram with 50\% Oxygen Enrichment (By Mass) 
FIGURE B-1

COMBUSTION PRODUCTS MOLLIER DIAGRAM WITH O\% OXYGEN ENRICHMENT

(BY M̈ASS)

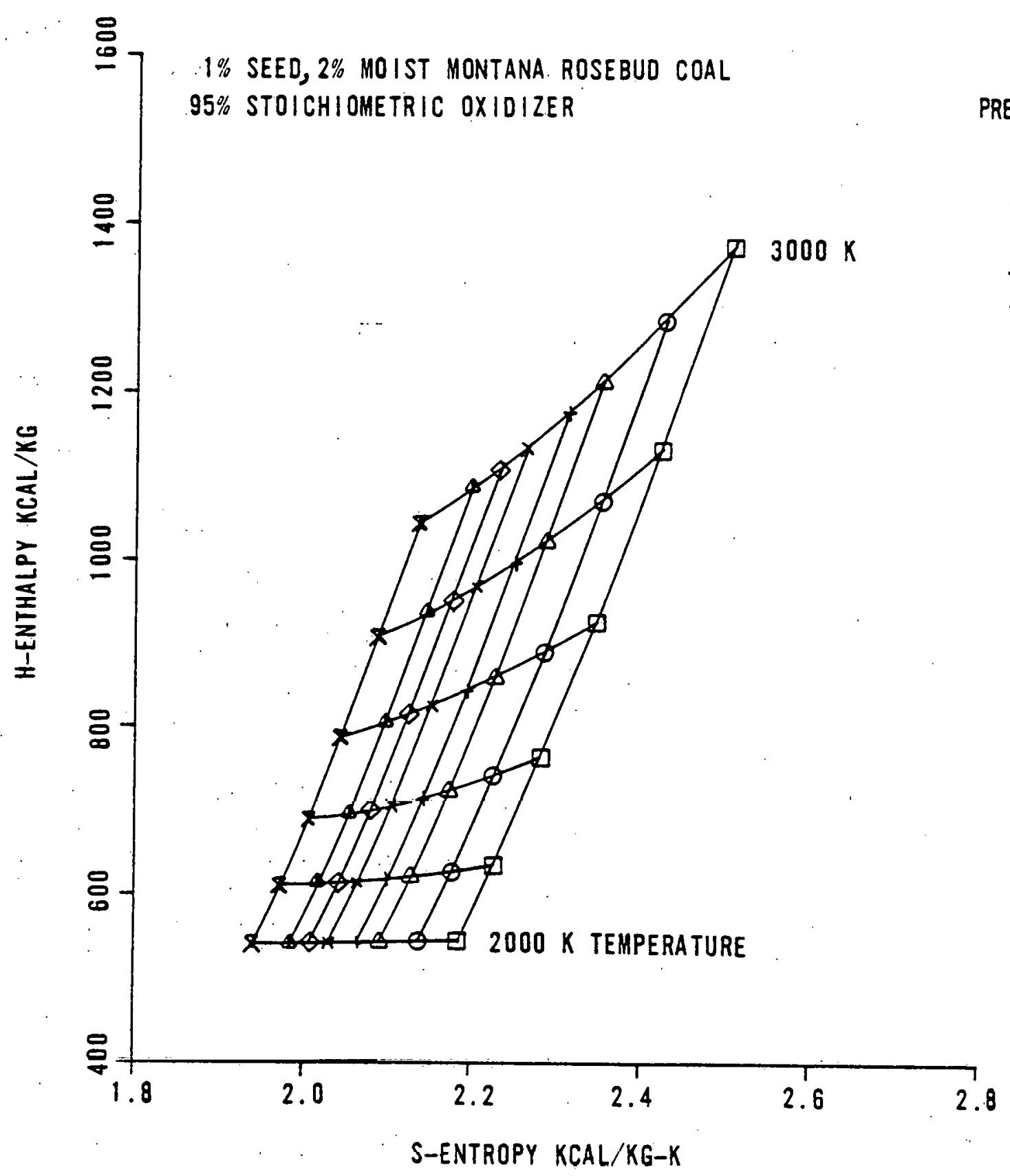




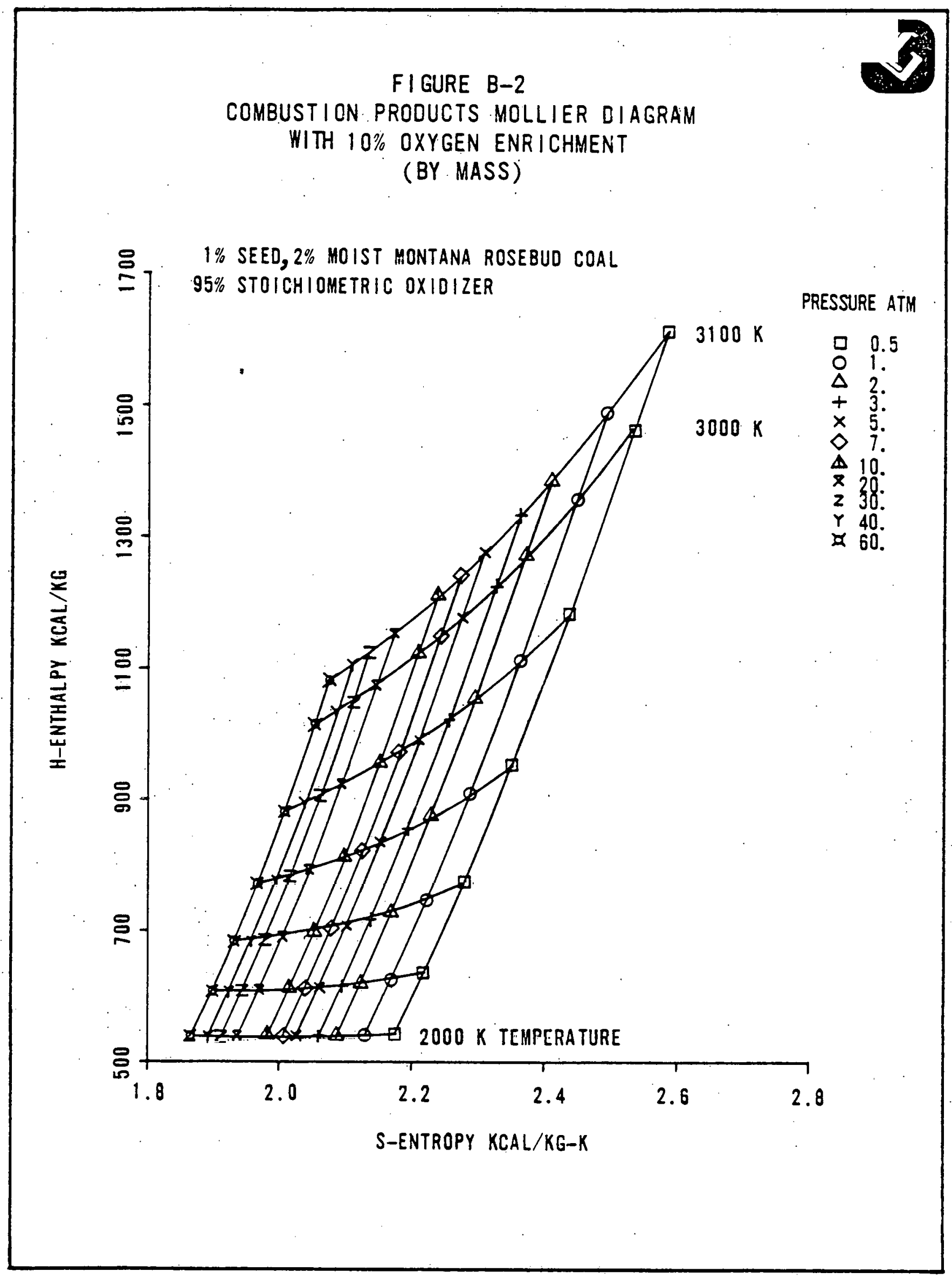




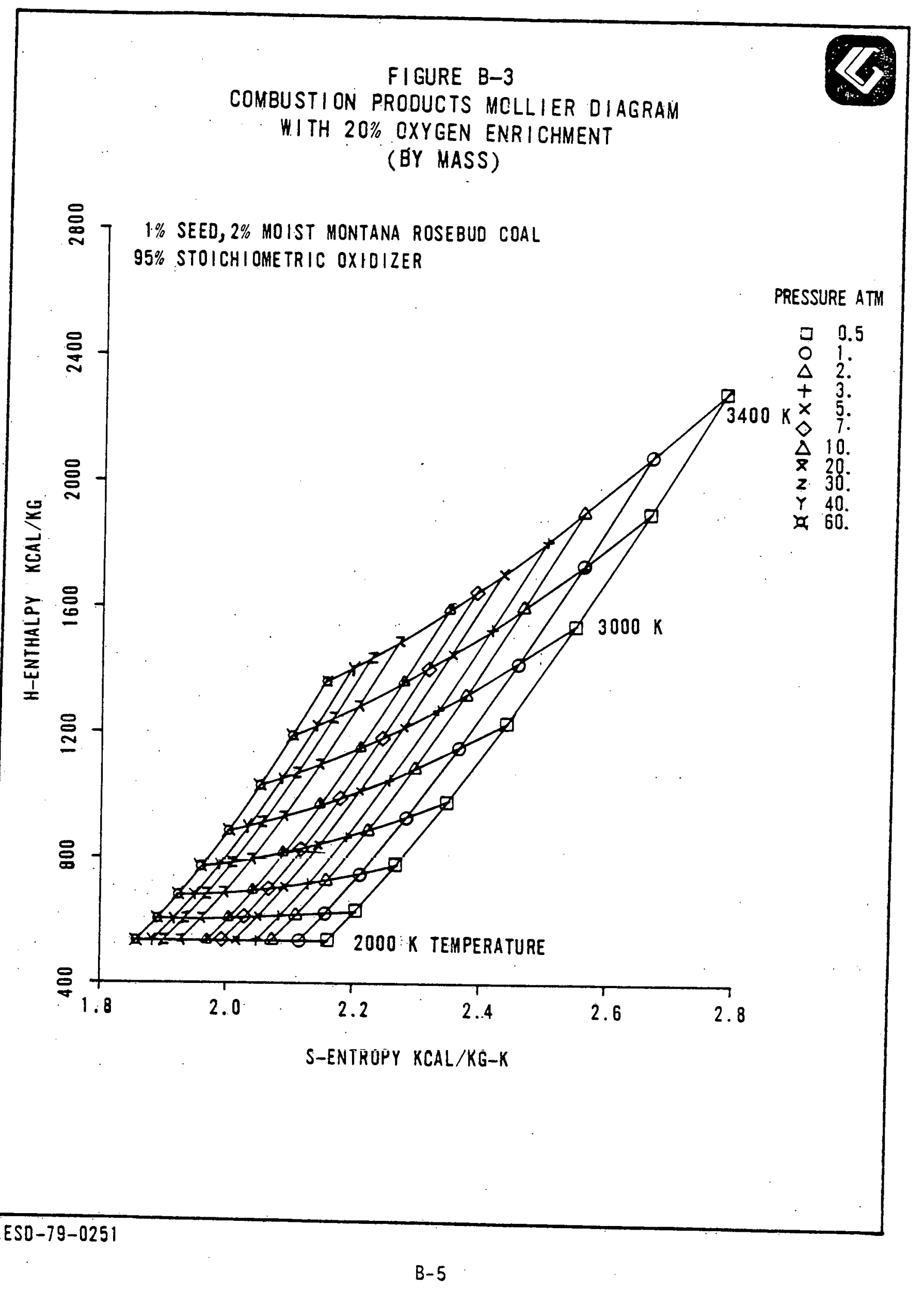




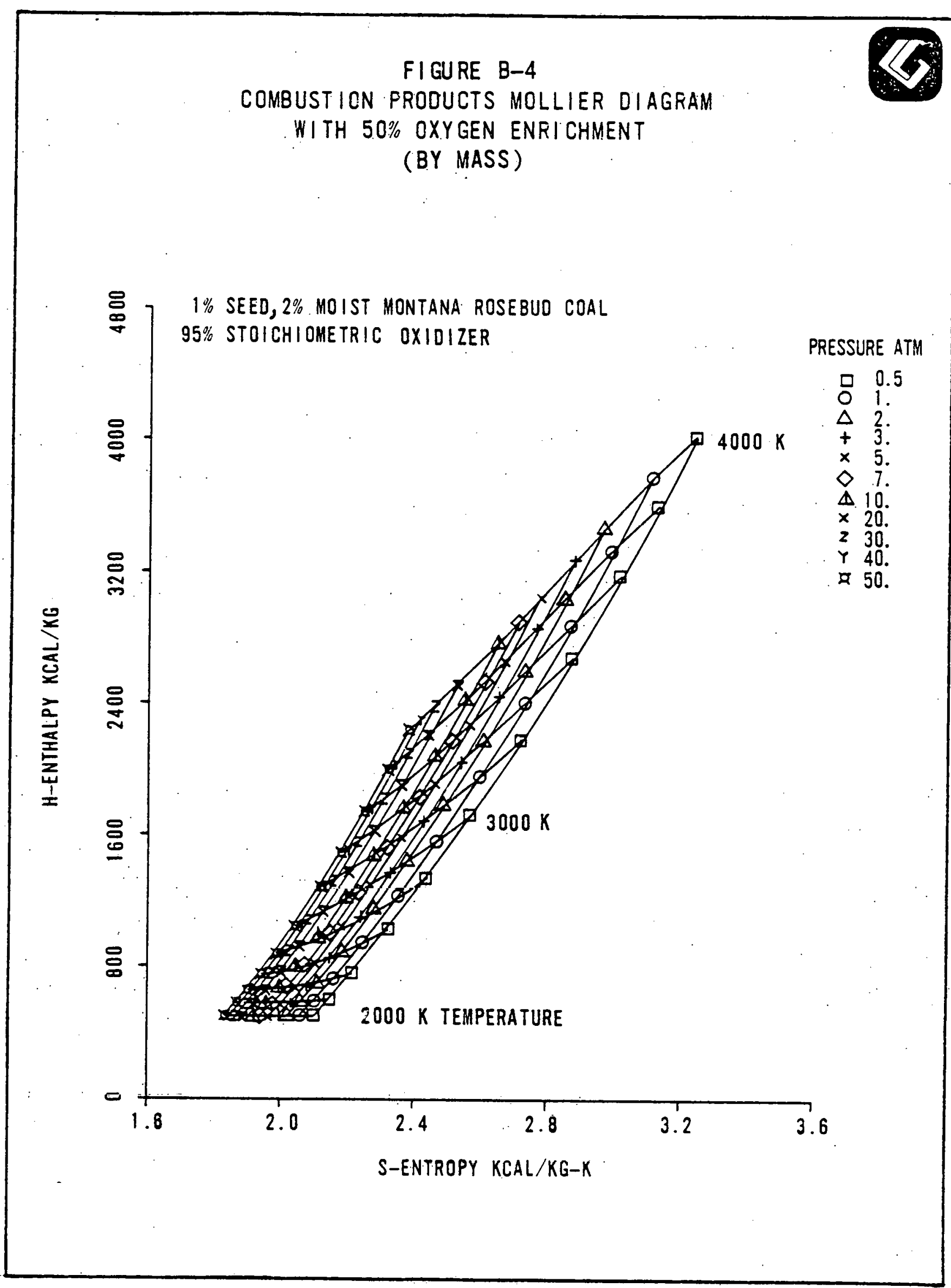

